\title{
Plant genome editing with TALEN and CRISPR
}

\author{
Aimee Malzahn', Levi Lowder ${ }^{2}$ and Yiping Qi ${ }^{1,3^{*}}$
}

\begin{abstract}
Genome editing promises giant leaps forward in advancing biotechnology, agriculture, and basic research. The process relies on the use of sequence specific nucleases (SSNs) to make DNA double stranded breaks at user defined genomic loci, which are subsequently repaired by two main DNA repair pathways: non-homologous end joining (NHEJ) and homology directed repair (HDR). NHEJ can result in frameshift mutations that often create genetic knockouts. These knockout lines are useful for functional and reverse genetic studies but also have applications in agriculture. HDR has a variety of applications as it can be used for gene replacement, gene stacking, and for creating various fusion proteins. In recent years, transcription activator-like effector nucleases and clustered regularly interspaced palindromic repeats (CRISPR) and CRISPR associated protein 9 or CRISPR from Prevotella and Francisella 1 have emerged as the preferred SSNs for research purposes. Here, we review their applications in plant research, discuss current limitations, and predict future research directions in plant genome editing.
\end{abstract}

Keywords: Plant genome editing, TALEN, CRISPR, Cas9, Cpf1, NHEJ, HDR

\section{Background}

The field of genome editing is experiencing rapid growth as new methods and technologies continue to emerge. Using genome editing to boost agriculture productivity is needed as the world population is expected to grow to 9.6 billion by 2050 while the amount of arable land decreases [1]. Besides potential for boosting crop yields, genome editing is now one of the best tools for carrying out reverse genetics and is emerging as an especially versatile tool for studying basic biology.

Genome edited plants are differentiated from conventional transgenic plants as they may not incorporate foreign DNA. Although genome editing can be used to introduce foreign DNA into the genome, it may simply involve changes of a few base pairs in the plant's own DNA. This distinction makes genome editing a novel and powerful breeding tool that has promising applications in agriculture, especially when genome

\footnotetext{
*Correspondence: yiping@umd.edu

${ }^{1}$ Department of Plant Science and Landscape Architecture, University of Maryland, College Park, MD 20742, USA

Full list of author information is available at the end of the article
}

edited crops are not regulated as genetically modified (GM) [2].

\section{Genome editing relies on DNA repair}

DNA damage occurs naturally in all cells either due to exogenous factors, such as UV radiation, or endogenous agents such as metabolic by-products and free radicals. A double-strand break (DSB) is the most lethal type of DNA damage and must be repaired before DNA replication, which has led to the evolution of two major DNA repair pathways in eukaryotes: non-homologous endjoining and homology-directed repair [3-6] (Fig. 1).

Non-homologous end-joining (NHEJ) is an error-prone repair pathway. When a DSB occurs, NHEJ can quickly, although often imprecisely, be used in two ways to repair the break. In classical NHEJ (Fig. 1a), several different proteins (e.g. Ku70 and Ku80) bind to broken DNA ends and are joined together by a ligase that can result in the insertion or deletion (indel) of nucleotides. In microhomology-based alternative NHEJ (Fig. 1b), $5^{\prime}$ ends are cut until $3^{\prime}$ overhangs with homology are created. DNA strands then bind at their complementary sequence, and flaps of non-homologous DNA are excised. This typically results in deletions as DNA between homologous sections 
a



b Microhomology Based Alternative NHEJ

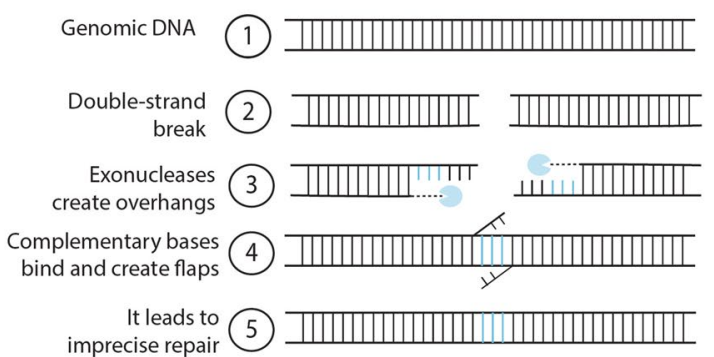

C

Homology Directed Repair
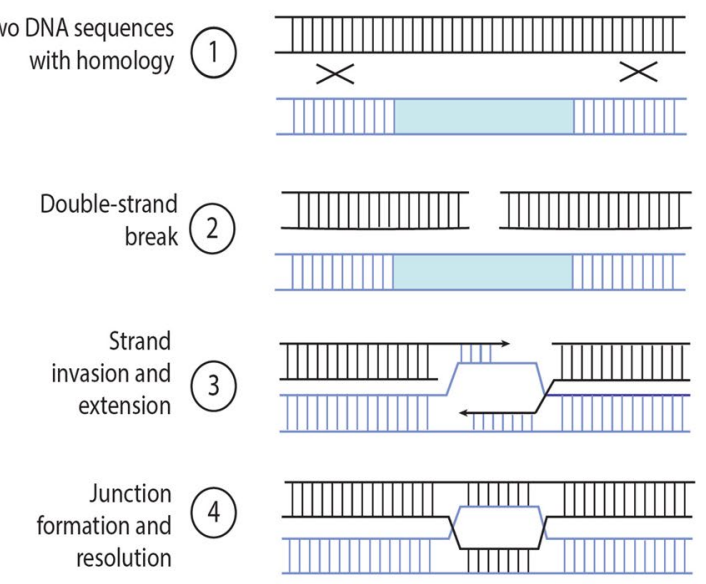

The result is precise
repair 5

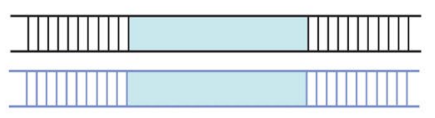

Fig. 1 Major DNA repair pathways in plants. Non-homologous end joining (NHEJ) and homology directed repair (HDR) are two main repair pathways. Classical NHEJ may lead to insertions or deletions, while microhomology based alternative NHEJ always results in deletions. Homology directed repair is less efficient, but can result in precise integration of a donor DNA template into the genome

are removed. NHEJ often leads to frameshift mutations which can result in premature stop codons, rendering genes non-functional (Fig. 1a, b). This is helpful for creating knockout plants useful for reverse genetic studies, but can also create desirable agricultural traits. For example, a powdery mildew resistant wheat line was created by knocking out three redundant $M L O$ genes [7].

The second DNA repair pathway is homology directed repair (HDR) which relies on template DNA. Homologous recombination is an important process that occurs in somatic cells to repair DSBs and in meiotically dividing cells to exchange genetic material between parental chromosomes. The most common conservative HDR mechanism in plants, which repairs almost all DSBs in somatic cells, is the synthesis-dependent strand annealing (SDSA) pathway $[4,8]$ (Fig. 1c). As a DSB occurs, $3^{\prime}$ overhangs are extended from the break site. A $5^{\prime}$ end invades the homologous strand forming a D-loop. Synthesis fills in the gaps using homologous DNA as a template, and the $3^{\prime}$ end reanneals with the second $3^{\prime}$ end without crossover. The result is a precisely integrated template or "donor" DNA strand. In nature, template DNA in the form of a sister chromatid or homologous chromosome is not always available, which may hinder HDR. However, synthetic template DNA can be provided exogenously and used for gene insertion, replacement, or epitope/ florescent tagging. There are many exciting applications in basic and applied science using HDR. For example, HDR was used to engineer an herbicide resistant trait in tobacco plants [9].

\section{Rapid evolution of sequence specific nucleases (SSNs) for plant genome editing}

Meganucleases, or homing endonucleases, are site specific endonucleases found in eukaryotes, archaea, and bacteria which recognize DNA sequences over 12 bp long [10]. Several hundred meganucleases have been discovered and they can be divided into four families: LAGLIDADG, His-Cys box, GIY-YIG, and the HNH family [10]. The LAGLIDADG family consists of popular meganucleases I-CreI and I-SceI. Originally, meganucleases were only able to target a single sequence and thus were not capable of targeting endogenous genes. After it was discovered that only a few amino acid residues make direct contact with nucleotides, the binding specificity was successfully altered for targeting endogenous genes. For example, targeted mutagenesis was successfully achieved in maize with de novoengineered meganucleases [11]. However, DNA binding properties of meganucleases cannot be completely separated from their nuclease activity, making them difficult to engineer and use in research. 
Zinc finger nucleases (ZFNs) function as dimers and each monomer is a fusion protein of a zinc finger DNA binding domain and a non-specific FokI nuclease domain [12, 13]. A zinc finger is formed by repeated groupings of cysteine and histidine residues and recognize 3 nucleotides (nt). Each ZFN monomer is typically composed of 3 or 4 zinc fingers, recognizing 9 or 12 nt DNA. The zinc fingers are thought to be modular, making it possible to recognize a long stretch of DNA by putting multiple zinc fingers together [14, 15]. However, ZFNs based on modular assembly typically have poor activity and high toxicity [16, 17], suggesting there is context dependency among neighboring fingers. This context dependency in ZFN engineering has been largely addressed by a proprietary platform developed by Sangamo Bioscience [18] and by academically developed platforms such as "OPEN" [19] and "CoDA" [20]. "OPEN" or "CoDA" generated ZFNs were later used for generating mutants and studying DNA repair mechanisms in the model plant Arabidopsis [21-23].

The possibility of engineering transcription activatorlike (TAL) effectors for DNA targeting was realized in 2009 when their DNA binding mechanism was discovered $[24,25]$. TAL effectors in nature are introduced into plant host cells by the bacterium Xanthomonas via the type III secretion system, where they alter host gene expression to meet the bacteria's needs. In the nucleus, TAL effectors bind target genes' promoters within 60 base pairs of start codons and activate transcription [24]. The DNA binding central repeat domain of each TAL effector is composed of a few to 33.5 repeats which are typically made of 34 amino acids [26]. Using a $\beta$-glucuronidase (GUS) reporter in tobacco, Boch et al. discovered repeat variable diresidue (RVD) at positions 12 and 13 of each repeat determines nucleotide binding specificity [25]. This breakthrough quickly led to the creation of a new kind of SSN called TAL effector nuclease (TALEN), which is based on the fusion of a Fok1 nuclease domain to the DNA binding TALE repeats [27-30] (Fig. 2a). There are benefits to choosing TALENs over ZFNs. First, TALEs are less toxic and secondly, they are easier to engineer because recognizing each DNA nucleotide simply relies on using a TALE repeat with the corresponding RVD. However, the repetitive sequence of TALE makes them difficult to construct via polymerase chain reaction (PCR). This was addressed with the development of multiple assembly methods mostly based on Golden gate cloning (e.g. [31-33]), which furthered rapid adoption of TALEN technology for genome editing in many organisms including plants.

Just 2 years after the realization of TALENs, another genome editing tool was introduced. Clustered regularly interspaced palindromic repeats (CRISPR) had been

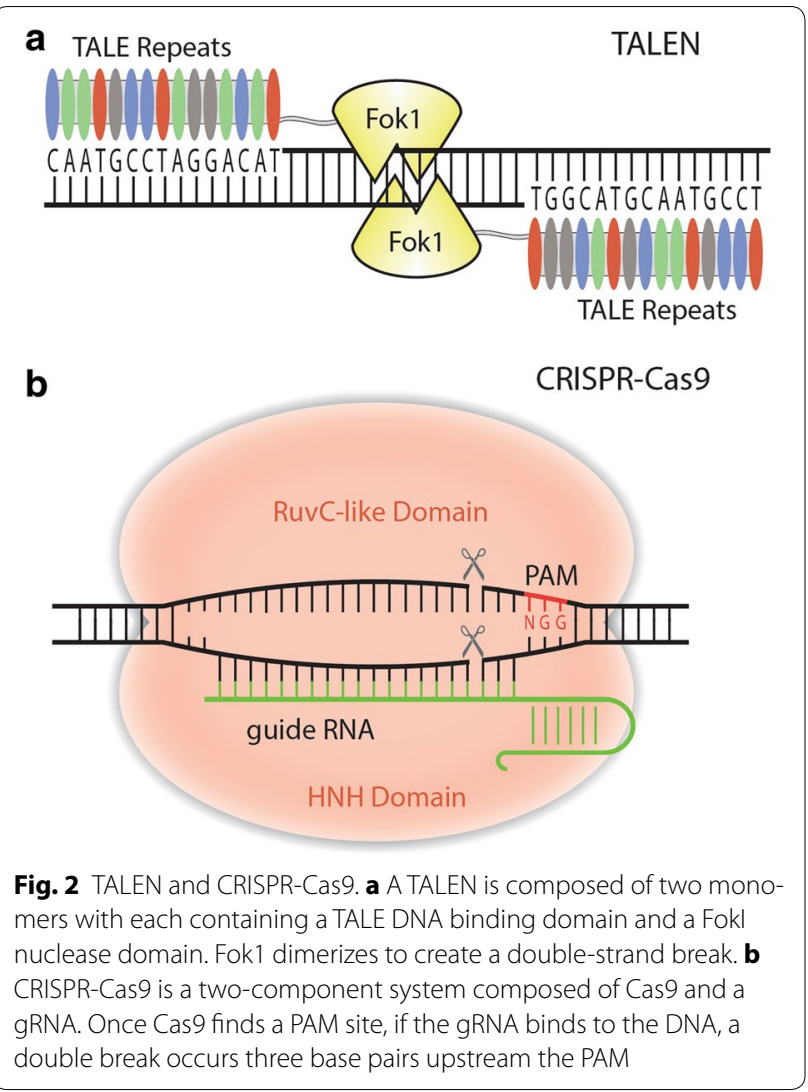

found to function as an adaptive immune system in bacteria and archaea against invading viruses, phages and plasmids [34-36]. The bacteria can protect themselves using a series of CRISPR associated (Cas) proteins that cleave viral DNA, insert pieces of viral DNA into their own genomes, and then use certain Cas9 protein(s) paired with RNA transcribed from the viral DNA library to make targeted double-strand breaks in invading viral DNA. Class 2 CRISPR-Cas systems utilize single-protein effectors, such as Cas9, for DNA targeting [37]. Cas9 is composed of two endonuclease domains, $\mathrm{HNH}$ and a RuvC-like domain that each cut one strand of DNA (Fig. 2b). It was demonstrated in 2012 that Cas9 of Streptococcus pyogenes could be paired with a synthetic single guide RNA (gRNA) to create a targeted DNA DSB in vitro and in Escherichia coli [38]. Shortly after, CRISPR-Cas9 was demonstrated as a powerful RNAguided SSN for genome editing in human cells [39, 40]. Although off target effects have been a concern, the simple design and ease of vector construction has dramatically increased the number of genome editing studies using CRISPR-Cas9 in plants [41, 42].

Both TALEN and CRISPR-Cas9 have been used extensively for genome editing and each have their own unique disadvantages and advantages (Table 1), that will be 
Table 1 Comparison of TALEN and CRISPR-Cas9 systems

\begin{tabular}{|c|c|}
\hline \multicolumn{2}{|l|}{ TALEN } \\
\hline Advantages & Disadvantages \\
\hline $\begin{array}{l}\text { 30 bp target requirement results } \\
\text { in less off-target effects }\end{array}$ & $\begin{array}{l}\text { Difficult protein engineering } \\
\text { potentially increases time and } \\
\text { financial investment }\end{array}$ \\
\hline \multirow{3}{*}{$\begin{array}{l}\text { No PAM requirement; can target } \\
\text { any sequence }\end{array}$} & Efficiency varies for each construct \\
\hline & Cannot target methylated DNA \\
\hline & Difficult to engineer nickase \\
\hline \multicolumn{2}{|l|}{ CRISPR-Cas9 } \\
\hline Advantages & Disadvantages \\
\hline Able to multiplex & $\begin{array}{l}\text { Higher potential for off-target } \\
\text { effects }\end{array}$ \\
\hline Easy to engineer & PAM requirement limits target \\
\hline \multicolumn{2}{|l|}{ Can target methylated DNA } \\
\hline Easy to create a nickase & \\
\hline
\end{tabular}

further explored in this review. Both systems will continue to be useful as molecular scissors for a wide variety of applications.

\section{NHEJ based genome editing by TALEN}

Over 50 genes have been targeted for mutations using TALEN in plants, including Arabidopsis, Barley, Brachypodium, maize, tobacco, rice, soybean, tomato and wheat (Table 2). Many of these have been proofof-concept studies. TALEN scaffolds were optimized for high activity in plants [43]. The optimized TALEN scaffold was then demonstrated by targeted mutagenesis in Arabidopsis [44], tomato [45], Brachypodium [46] and wheat [7]. More recently, TALEN was shown to induce a variety of heritable mutations in rice [47], demonstrating its usefulness in plant genome editing.

As an effective genome editing tool, TALEN has been applied to generate useful traits in crops. In an elegant study, TALEN was used to engineer disease resistance in Xanthomonas oryzae pv. oryzae by destroying the target sequence of TALE effectors in rice [48]. In soybean, the FAD2 gene was targeted for improved oil quality [49]. In wheat, three homologs of $M L O$ were successfully targeted for simultaneous knockout, conferring heritable disease resistance to powdery mildew [7]. Improved

Table 2 TALEN mediated genome editing in plants

\begin{tabular}{|c|c|c|c|}
\hline Plant species & Target gene & Modification & Reference \\
\hline Arabidopsis & ADH1, TT4, MAPKKK1, DSK2B, NATA2, GLL22a, GLL22b & NHEJ & {$[31,44]$} \\
\hline Arabidopsis & CLV3 & NHEJ & {$[134]$} \\
\hline Arabidopsis & CRU3 & NHEJ & {$[135]$} \\
\hline Barley & HvPAPhy_a & NHEJ & {$[136]$} \\
\hline Barley & GFP (transgene) & NHEJ & {$[137]$} \\
\hline Barley & GFP (transgene) & HDR & {$[92]$} \\
\hline Brachypodium & ABA1, CKX2, SMC6, SPL, SBP, COII, RHT, HTA1 & NHEJ & {$[46]$} \\
\hline Maize & $G L 2$ & NHEJ & {$[138]$} \\
\hline Maize & IPK1A, IPK, MRP4 & NHEJ & {$[139]$} \\
\hline Nicotiana benthamiana & FucT, XylT & NHEJ & {$[140]$} \\
\hline Nicotiana tabacum & $A L S$ & NHEJ, HDR & {$[43]$} \\
\hline Potato & VInv & NHEJ & {$[52]$} \\
\hline Potato & $A L S$ & NHEJ & {$[141,142]$} \\
\hline Rice & $11 N 3$ & NHEJ & {$[48]$} \\
\hline Rice & $D E P 1, B A D H 2, C K X 2, S D 1$ & NHEJ & {$[46,50]$} \\
\hline Rice & EPSPS & NHEJ & {$[143]$} \\
\hline Rice & MST7, MST8, PMS3, CSA, DERF1 & NHEJ & {$[47]$} \\
\hline Rice & $\operatorname{LOX} 3$ & NHEJ & {$[51]$} \\
\hline Rice & $A L S$ & HDR & [93] \\
\hline Rice & SWEET14 & NHEJ & {$[144]$} \\
\hline Rice & WAXY & NHEJ & {$[145]$} \\
\hline Soybean & FAD2-1A, FAD2-1B, FAD3A & NHEJ & {$[49,146]$} \\
\hline Soybean & PDS11, PDS18 & NHEJ & {$[147]$} \\
\hline Sugarcane & COMT & NHEJ & {$[148]$} \\
\hline Tomato & PROCERA & NHEJ & {$[45]$} \\
\hline Tomato & ANT1 & HDR & {$[94]$} \\
\hline Wheat & MLO & NHEJ & [7] \\
\hline
\end{tabular}


rice seeds have been engineered with TALEN, creating traits such as fragrance [50] and storage tolerance [51]. Improved cold storage and processing traits have also been engineered in potato [52].

Most of these studies targeted protein coding genes for mutagenesis (Fig. 3a). Other types of NHEJ based editing can also be achieved by TALEN, such as targeted mutagenesis of non-protein coding genes (Fig. $3 \mathrm{~b}$ ) and regulatory elements [48] (Fig. 3c), and generating large chromosomal deletions [44] (Fig. 3d).

\section{NHEJ based genome editing by CRISPR-Cas9}

Due to ease of engineering, CRISPR-Cas9 has been widely adopted for genome editing in plants (Table 3). At the time of this review, CRISPR-Cas9 edited plants include Arabidopsis, barley, Brassica oleracea, cotton, dandelion, flax, lettuce, liverwort, corn, petunia, populus, rice, sorghum, soybean, sweet orange, tomato, wheat, and several tobacco varieties (Table 3). CRISPR-Cas9 quickly moved beyond proof-of-concept; promoting a reverse genetics revolution in plant research and creating many desirable traits in major crops. Using rice as an example, multiple yield-related genes have been targeted in rice [53]. CRISPR-Cas9 has been widely used for functional study on rice genes (Table 3). In addition, environmentinduced male sterility has been engineered to facilitate hybrid-based breeding [54, 55]. Disease resistance traits have been developed by knocking out host genes in rice [56] and Arabidopsis [57].

The intrinsic property of CRISPR-Cas9 for targeting viral DNA for cleavage makes it a great tool to increase plant immunity against DNA viruses. For example, such

\section{Protein Coding Genes}

a

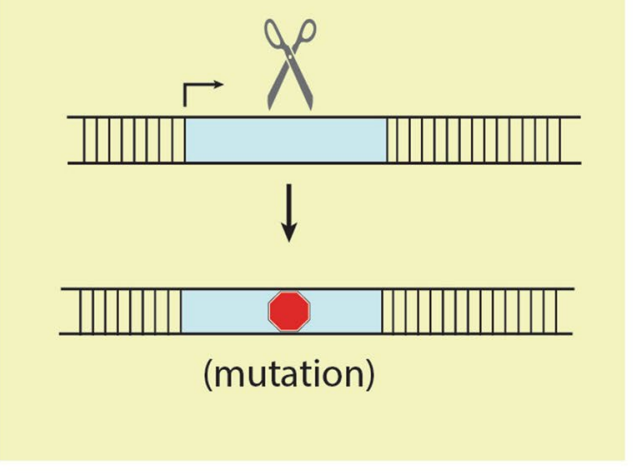

Regulatory Elements

C

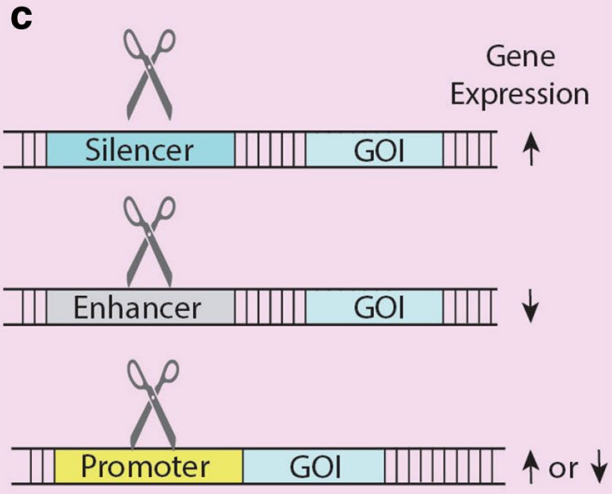

Non-Protein Coding Genes

b

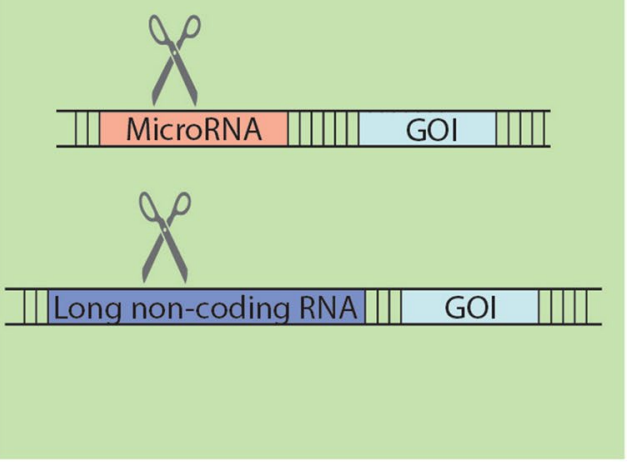

\section{Chromosomal Deletion}

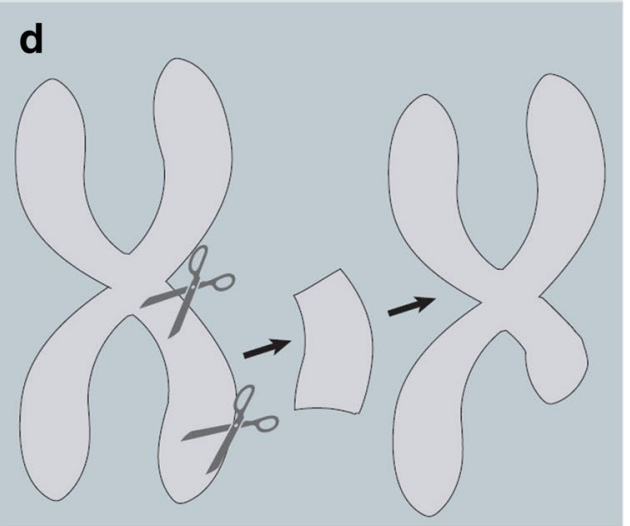

Fig. 3 NHEJ based genome editing applications. a NHEJ repair of an SSN induced break can create a premature stop codon. A stop codon is indicated by a red octagon. GOI is an acronym for gene of interest. b Non-protein coding genes such as microRNA and long non-coding RNA can be rendered non-functional through targeted mutations by SSNs. c Regulatory elements involved in the activation or repression of genes can be disrupted by SSNs. d Pieces of chromosomes that may involve regulatory networks or related genes can be deleted by SSNs 
Table 3 CRISPR-Cas9 mediated genome editing in plants

\begin{tabular}{|c|c|c|c|}
\hline Plant species & Target gene & Modification & Reference \\
\hline Arabidopsis & PDS3, FLS2, RACK1b, RACK1C & NHEJ & {$[96]$} \\
\hline Arabidopsis & $B R / 1, G A I, J A Z 1$ & NHEJ & {$[149,150]$} \\
\hline Arabidopsis & CHLI1, CHLI2, TT4, AP1, GL2 & NHEJ & {$[150-152]$} \\
\hline Arabidopsis & GFP (transgene) & NHEJ & {$[153,154]$} \\
\hline Arabidopsis & ADH1, TT4, RTEL, GUS (transgene) & NHEJ, HDR & {$[85,86]$} \\
\hline Arabidopsis & $F T, S P L 4$ & NHEJ & {$[155]$} \\
\hline Arabidopsis & $A B P 1$ & NHEJ & {$[71]$} \\
\hline Arabidopsis & Cru3 & NHEJ & {$[156]$} \\
\hline Arabidopsis & TRY, CPC, ETC2, CHIL 1, CHIL2 & NHEJ & {$[79,157]$} \\
\hline Arabidopsis & $1 g 03180,1 g 16210,1 g 56650,5 g 55580$ & NHEJ & {$[80]$} \\
\hline Arabidopsis & $05 g 55580,1 g 56650,1 g 03180,1 g 16210$ & NHEJ & {$[80]$} \\
\hline Arabidopsis & PHYB, BRI1 & NHEJ & {$[123]$} \\
\hline Arabidopsis & $B R / 1, P D S 3$ & NHEJ & {$[158]$} \\
\hline Arabidopsis & PYR1, PYL1, PYL2, PYL4, PYL5, PYL8 & NHEJ & {$[82]$} \\
\hline Arabidopsis & SH3P3 & NHEJ & {$[159]$} \\
\hline Arabidopsis & elF(iso)4E & NHEJ & {$[57]$} \\
\hline Arabidopsis & $C B F 1, C B F 2, C B F 3$ & NHEJ & {$[63,160]$} \\
\hline Arabidopsis & $D M 2$ & NHEJ & {$[161]$} \\
\hline Arabidopsis & UGT79B2, UGT79B3 & NHEJ & {$[162]$} \\
\hline Arabidopsis & CWIN1 & NHEJ & {$[163]$} \\
\hline Arabidopsis & MIR169a, MIR827a, TFL1 & NHEJ, HDR & {$[77]$} \\
\hline Arabidopsis & TTG1 & NHEJ & {$[164]$} \\
\hline Barley & HVPM19 & NHEJ & {$[165]$} \\
\hline Cabbage & BolC.GA4.a & NHEJ & {$[165]$} \\
\hline Camelina & FAD2 & NHEJ & {$[69,70]$} \\
\hline C. reinhardtii & CPFTSY, ZEP & NHEJ & {$[166]$} \\
\hline Cotton & GFP (transgene) & NHEJ & {$[167]$} \\
\hline Cotton & MYB25-like A, MYB25-like D & NHEJ & {$[67]$} \\
\hline Cotton & $C L A 1, V P$ & NHEJ & {$[68]$} \\
\hline Dandelion & $1-F F T$ & NHEJ & {$[168]$} \\
\hline Flax & EPSPS, BFP (transgene) & NHEJ, HDR & {$[169]$} \\
\hline Grape & $I d n D H$ & NHEJ & {$[170]$} \\
\hline Lettuce & BIN2 & NHEJ & {$[123]$} \\
\hline Liverwort & $A R F 1$ & NHEJ & {$[171]$} \\
\hline Lotus japonicus & SYMRK, LjLb1, LjLb2, LjLb3 & NHEJ & {$[172]$} \\
\hline Maize & IPK & NHEJ & {$[139]$} \\
\hline Maize & $L I G 1, M s 26, M s 45, A L S 1, A L S 2$ & NHEJ, HDR & {$[173]$} \\
\hline Maize & PSY1, and other 90 loci & NHEJ & {$[174]$} \\
\hline Maize & ZB7, 2g332562, 2g080129, 2g099580, 2g170586, 2g438243, & NHEJ & {$[175]$} \\
\hline Maize & ARGOS8 & NHEJ & {$[176]$} \\
\hline Maize & AGO18a, Ago18b, a1, a4 & NHEJ & {$[177]$} \\
\hline Moss & PpAPT & NHEJ, HDR & {$[178]$} \\
\hline Moss & PpKAI2L, PpAP2/ERF & NHEJ & {$[179]$} \\
\hline N. oceanica & $N R$ & NHEJ & {$[180]$} \\
\hline N. attenuata & $A O C$ & NHEJ & {$[123,159]$} \\
\hline N. benthamiana & PDS3 & NHEJ, HDR & {$[96]$} \\
\hline N. benthamiana & PDS & NHEJ & [181-183] \\
\hline N. benthamiana & PCNA, PDS & NHEJ & {$[60]$} \\
\hline N. benthamiana & FLS2, BAK1 & NHEJ & {$[81]$} \\
\hline
\end{tabular}


Table 3 continued

\begin{tabular}{|c|c|c|c|}
\hline Plant species & Target gene & Modification & Reference \\
\hline N. benthamiana & PDS, blspH & NHEJ & {$[184]$} \\
\hline N. benthamiana & $X T 1, X T 2$ & NHEJ & {$[185]$} \\
\hline N. benthamiana & EDS1a, PAD4 & NHEJ & {$[161]$} \\
\hline N.tabacum & GFP (transgene) & NHEJ & {$[153]$} \\
\hline N.tabacum & PDS, PDR6 & NHEJ & {$[186]$} \\
\hline N.tabacum & mCherry (transgene) & NHEJ & {$[187]$} \\
\hline Petunia & PDS & NHEJ & [188] \\
\hline Petunia & $N R$ & NHEJ & [189] \\
\hline Populus & $4 C L 1,4 C L 2,4 C L 5$ & NHEJ & {$[64]$} \\
\hline Populus & PDS & NHEJ & {$[190,191]$} \\
\hline Potato & $\mid A A 2$ & NHEJ & {$[192]$} \\
\hline Potato & $A L S$ & NHEJ & {$[142,193]$} \\
\hline Potato & GBSS & NHEJ & {$[194]$} \\
\hline Potato & MYB44 & NHEJ & {$[195]$} \\
\hline Rice & PDS, BADH2, MPK2, $02 g 23823$ & NHEJ & {$[65,83]$} \\
\hline Rice & MPK5 & NHEJ & {$[196]$} \\
\hline Rice & ROC 5, SPP, YSA & NHEJ & {$[149,197]$} \\
\hline Rice & MYB1 & NHEJ & {$[151,197]$} \\
\hline Rice & DERF1, EPSPS, MSH1, PDS, PMS3 & NHEJ & {$[197]$} \\
\hline Rice & SWEET11 & NHEJ & {$[198]$} \\
\hline Rice & SWEET11, SWEET14 & NHEJ & {$[153]$} \\
\hline Rice & CAO1, LAZY1 & NHEJ & [199] \\
\hline Rice & $B E L$ & NHEJ & {$[200]$} \\
\hline Rice & SWEET11, SWEET13, SWEET1a, SWEET16, CPS4, CYP99A2, CYP76M5, CYP76M6, KO1, KOL5 & NHEJ & {$[76]$} \\
\hline Rice & $C D K A 2, C D K B 1, C D K B 2$ & NHEJ & {$[201]$} \\
\hline Rice & MPK1, MPK2, MPK5, MPK6, PDS & NHEJ & {$[202]$} \\
\hline Rice & $A L S$ & HDR & {$[97,98]$} \\
\hline Rice & GSTU, MRP15, ANP, WAXY, 7FTL genes, and 21 other genes & NHEJ & {$[80]$} \\
\hline Rice & $A O X 1 a, A O X 1 b, A O X 1 c, B E L$ & NHEJ & {$[203]$} \\
\hline Rice & DsRed (transgene), YSA, PDS, DL & NHEJ & {$[204,205]$} \\
\hline Rice & P450, DWD1 & NHEJ & {$[123]$} \\
\hline Rice & RAV2 & NHEJ & {$[78]$} \\
\hline Rice & $D M C 1 A, D M C 1 B$ & NHEJ & {$[87]$} \\
\hline Rice & $N A L 1, L P A 1, L G 1, G L 1-1$ & NHEJ & {$[206]$} \\
\hline Rice & DEP1, ROC5 & NHEJ & {$[207]$} \\
\hline Rice & Gn1a, DEP1, GS3, IPA 1 & NHEJ & {$[53]$} \\
\hline Rice & ERF922 & NHEJ & {$[56]$} \\
\hline Rice & OST2 & NHEJ & {$[208]$} \\
\hline Rice & CSA & NHEJ & {$[54]$} \\
\hline Rice & RUPO & NHEJ & [209] \\
\hline Rice & EPSPS & NHEJ, HDR & {$[210]$} \\
\hline Rice & TMS5 & NHEJ & {$[55]$} \\
\hline Rice & $P M R$ & NHEJ & {$[211]$} \\
\hline Rice & MEGs, PEGs & NHEJ & {$[212]$} \\
\hline Rice & $\mathrm{Hd} 2, \mathrm{Hd} 4, \mathrm{Hd} 5$ & NHEJ & [213] \\
\hline Rice & SBEI, SBEIIB & NHEJ & {$[214]$} \\
\hline Rice & $A C T, G S T$ & HDR & [99] \\
\hline Rice & $\mathrm{RBOHH}$ & NHEJ & {$[215]$} \\
\hline Rice & EPFL9 & NHEJ & [116] \\
\hline
\end{tabular}


Table 3 continued

\begin{tabular}{|c|c|c|c|}
\hline Plant species & Target gene & Modification & Reference \\
\hline Salvia miltiorrhiza & CPS1 & NHEJ & [216] \\
\hline Sorghum & DsRED2 (transgene) & NHEJ & [153] \\
\hline Soybean & GFP (transgene), 07g14530, 01g38150, 11g07220, miR1514, miR1509 & NHEJ & [217] \\
\hline Soybean & $06 g 14180,08 g 02290,09 g 00490,12 g 37050$ & NHEJ & [218] \\
\hline Soybean & PDS11, PDS18 & NHEJ & [147] \\
\hline Soybean & DD20, DD43, ALS & NHEJ, HDR & [219] \\
\hline Soybean & FEl1, FEI2, SHR, bar (transgene) & NHEJ & [220] \\
\hline Soybean & Rj4 & NHEJ & [72] \\
\hline Sweet orange & PDS & NHEJ & [221] \\
\hline Sweet orange & $\angle O B 1$ & NHEJ & [222] \\
\hline Tomato & SHR, GFP (transgene) & NHEJ & [223] \\
\hline Tomato & $A G O, 08 g 041770,07 g 021170,12 g 044760$ & NHEJ & [224] \\
\hline Tomato & RIN & NHEJ & {$[225]$} \\
\hline Tomato & PDS, PIF4 & NHEJ & [226] \\
\hline Tomato & SIAGL6 & NHEJ & [227] \\
\hline Tomato & SP5G & NHEJ & [228] \\
\hline Tomato & SIBOP & NHEJ & [229] \\
\hline Tomato & SIIAA9 & NHEJ & [230] \\
\hline Tomato & $M L O$ & NHEJ & [231] \\
\hline Wheat (common) & MLO & NHEJ & {$[7,65]$} \\
\hline Wheat (common) & INOX & NHEJ & [183] \\
\hline Wheat (common) & GASR7, GW2, DEP1, NAC2, PIN1, LOX2, & NHEJ & {$[66]$} \\
\hline Wheat (common) & Ubi, MLO & HDR & {$[100]$} \\
\hline Wheat (Durum) & GASR7 & NHEJ & {$[66]$} \\
\hline
\end{tabular}

immunity has been shown in tobacco by stably expressing Cas9 and introducing gRNAs that target geminiviruses [58]. Many similar studies have targeted geminiviruses because they must maintain circular structure for replication, thus one DSB will destroy the virus [59]. Tobacco with resistance to the geminiviruses beet severe curly top virus, bean yellow dwarf virus, and tomato yellow leaf curl virus have been created [58, 60,61]. These findings were also replicated in Arabidopsis [61]. Because Cas9 can complex with any compatible and programmable gRNAs, it may offer a robust protection strategy against double stranded DNA viruses. Single stranded viruses can also be potentially targeted by NMCas9 which exhibit DNase $\mathrm{H}$ activity [62].

CRISPR-Cas9 is a valuable reverse genetic tool in plant science research. Large chromosomal deletion in Arabidopsis was used to demonstrate redundant functionality of tandem arrayed $C B F$ genes in cold acclimation [63] (Fig. 3d). CRISPR-Cas9 based reverse genetics was even made possible in poplar [64], a woody tree that has traditionally proven difficult for genetic manipulation. Despite challenges with editing polyploidy plants, both hexaploid bread wheat and tetraploid durum wheat were effectively edited by CRISPR-Cas9 $[7,65,66]$. Editing of the tetraploid cotton genome was also recently reported $[67,68]$. Camelia sativa is a hexaploid relative to Arabidopsis and editing three copies of the FAD2 gene was demonstrated when screen was carried to T3 generation [69, 70]. Using CRISPR-Cas9, two recent studies disproved conclusions made by earlier work using traditional genetic techniques, further demonstrating that CRISPR-Cas9 is a great addition to existing genetic tools. In one study, knockout alleles of $A B P 1$ were generated in Arabidopsis and it was discovered this gene is not required for auxin signaling or development as originally thought [71]. In another study [72], Rj4 was found to control nodulation specificity in soybean and the identity of this gene confirmed by CRISPR-Cas9 corrected earlier reports.

CRISPR-Cas9 will also further reverse genetic studies on non-protein coding genes (Fig. 3b) and regulatory elements (Fig. 3c). MicroRNAs are short RNAs that can repress translation, but mostly cleave mRNA transcripts [73]. Both mechanisms silence protein expression. Long non-coding RNAs are diverse groups of noncoding transcripts longer than 200 nucleotides whose function is poorly understood in plants [74]. Small indel mutations in non-protein coding genes may not alter or destroy their function, making them more challenging targets with CRISPR-Cas9 [75]. CRISPR-Cas9 mediated 
targeted chromosomal deletion is very efficient in rice [76] and this approach was recently applied for deleting microRNA genes in Arabidopsis [77]. Moreover, CRISPRCas9 was used to target a non-coding regulatory element of OsRAV2 in rice to confirm its function in response to salt treatment [78].

\section{Multiplex CRISPR-Cas9 systems}

One distinct advantage of CRISPR-Cas9 over TALEN is the ability to multiplex (Table 1). By expressing multiple gRNAs that independently pair with Cas9, multiple target sites can be mutated in a single cell. This multiplexing property of CRISPR-Cas9 has enabled targeted deletion of large chromosomal segments containing multiple genes in rice [76] and in Arabidopsis [63]. Simultaneous targeting of multiple genes can result in more than one improved trait in crops, and can also be used in basic research to deduce the role of each gene in a complex network.

The first toolkit to demonstrate multiplexing knockout of three Arabidopsis genes was released in 2014 [79]. Since then, several toolkits have been developed. A second toolkit was released in 2015 by Ma et al. [80], that constructed vectors using PCR and Golden Gate cloning. These constructs were validated in both monocots and dicots. A third toolkit was released in that same year by Lowder et al. [81]. This kit contains vectors that could be used for genome editing and transcriptional regulation without the need for PCR, ensuring that no mutations occur during assembly. Other multiplex systems were also developed that, while more time consuming, allowed for targeting of up to six target sites or theoretically unlimited target sites respectively $[82,83]$.

\section{Paired CRISPR-Cas9 nickase for improving editing specificity}

TALEN works in pairs to recognize $30 \mathrm{bp}$ or even longer DNA sequences and presumably has higher targeting specificity than CRISPR-Cas9 which recognizes $\sim 20$ bp DNA sequence. However, the targeting specificity of CRISPR can be improved by using a paired nickase strategy (Fig. 4a). One of the Cas9 endonuclease domains, either $\mathrm{HNH}$ or RuvC-like, is inactivated to produce a Cas9 nickase that can only cut one DNA strand. By pairing two nickases and their gRNAs, the target sequence grows from $\sim 20$ to $\sim 40 \mathrm{bp}$ and specificity is drastically increased. It was shown this increase in specificity results in a 20- to 1500-fold reduction in off-target effects without a decrease in cleavage efficiency in human cells [84]. There are several examples of successful genome editing using nickases in plants [85-87]. A single transcript unit (STU) was effectively shown to express Cas9 nickase and a gRNA pair [88], in which Cas9 and two gRNAs flanked by hammerhead ribozyme sequences were expressed under a single Polymerase II promoter. The ribozyme successfully processed the single transcript, demonstrating a system for simultaneous, inducible expression of both Cas9 and gRNAs.

Alternatively, FokI-dCas9 can be engineered to work in pairs $[89,90]$, which relies on fusing a catalytically dead Cas9 (dCas9) with a FokI nuclease domain (Fig. 4b). When the two Fok1-dCas9s are carefully positioned on both DNA strands, the gRNAs lead dCas9 to the target sites and FokI nuclease domains dimerize resulting in DNA cleavage. As with the paired nickase strategy, the requirement of two gRNAs should decrease off-target effects. This takes advantage of the simple design of gRNAs and avoids the protein engineering required for TALEN. However, the editing frequency for both techniques will need to be improved for wide-scale adoption.

\section{HDR based genome editing with TALEN and CRISPR-Cas9}

There are many powerful applications for HDR based genome editing using both TALEN and CRISPR-Cas9. The applications include, but are not limited to, gene replacement (Fig. 5a), epitope tagging (Fig. 5b) or florescent protein tagging (Fig. 5c) of endogenous genes, and gene insertion which can be used for trait stacking (Fig. 5d).

Gene replacement with HDR was first accomplished using TALENs in human cells in 2011 [91], but it wasn't until 2013 that HDR initiated by TALEN was demonstrated in plants [43] (Table 2). Barley was the first monocot to demonstrate HDR with TALEN. A green fluorescent protein (GFP) was converted into yellow fluorescent protein (YFP) by one amino acid change with a 3\% efficiency in protoplasts, demonstrating an effective system for optimizing TALENs [92]. Replacing $A L S$ with an herbicide resistant gene was successful in tobacco protoplasts and rice with TALEN [43, 93]. In the tobacco protoplasts, about $30 \%$ of transformed cells had NHEJ mutations and 14\% showed targeted insertion due to HDR [43]. For this study, transient expression of TALEN was efficient enough to get edited plants without selection. In rice, it was reported that between 1.4 and $6.3 \%$ of transformants had one or both alleles edited [93]. In tomato, targeted insertion of a strong promoter ahead of the ANT1 gene led to ectopic accumulation of anthocyanin, producing purple tomatoes [94]. The study utilized a geminivirus replicon system that has the advantage of amplifying the genome editing reagents in plant cells [95].

HDR utilizing CRISPR-Cas9 was first demonstrated in 2013 [96] (Table 3). A plant codon-optimized Cas9 and gRNAs were transiently expressed in Arabidopsis and 


\section{a}
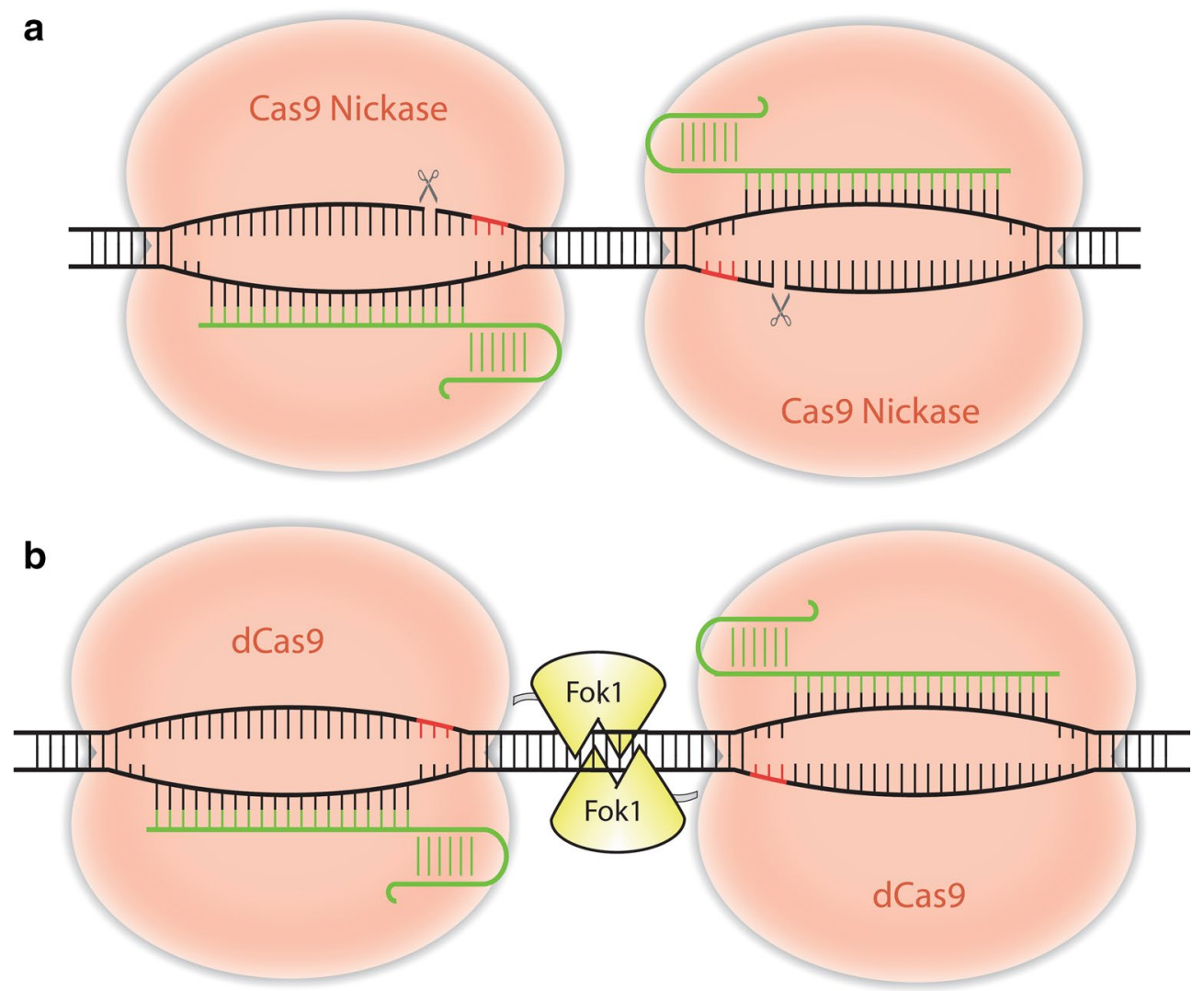

Fig. 4 Paired Cas9 nickase and Fokl-dCas9 systems. Alternative Cas9 proteins can decrease off-target effects. a Two nickases are required to make a double-strand break, increasing the gRNA requirement and length of target sequence. b A catalytically dead Cas9 is paired to a Fok1 nuclease, also resulting in an increased length of target sequence for enhanced targeting specificity

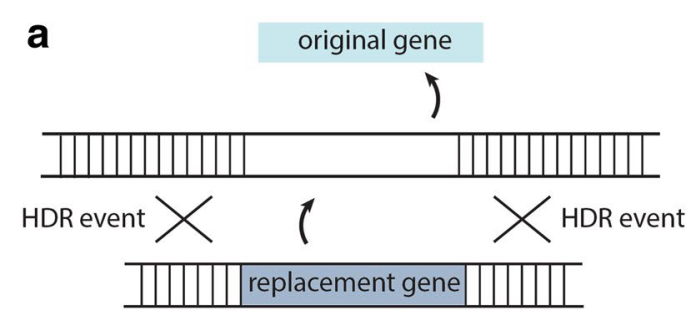

C

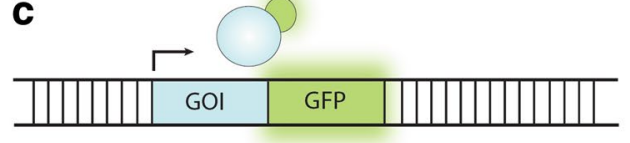

b

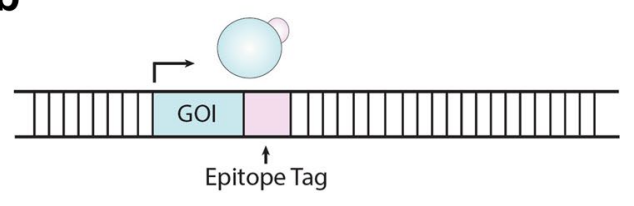

d

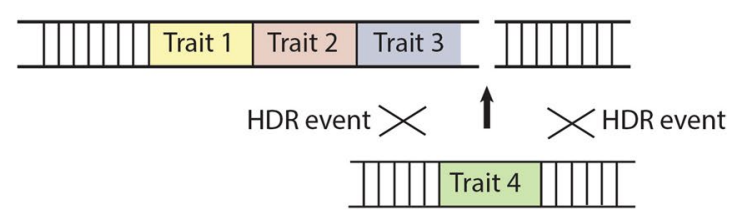

Fig. 5 HDR based genome editing applications. a Gene replacement is applicable for basic research and agriculture. $\mathbf{b}$ HDR can add a tag to a protein for easy purification and study. c Fluorescent proteins such as green fluorescent protein (GFP) can be fused to a gene of interest for in vivo study. $\mathbf{d}$ Gene stacking is useful for placing genes physically close together on a chromosome. This is accomplished by creating a target site for HDR at the end of each gene, which allows for modular addition of genes 
tobacco protoplasts for targeting respective PDS genes. A much higher mutagenesis frequency was observed in the tobacco protoplasts compared to Arabidopsis. HDR was accomplished at $9 \%$ frequency with a donor template harboring an AvrII digestion site, a 533 bp left homology arm, and a $114 \mathrm{bp}$ right homology arm. This proof-of-concept study demonstrated that it is possible to replace a wildtype gene with an altered one using CRISPR-Cas9 in plant cells. A year later, germline editing of the $A D H 1$ gene was demonstrated in Arabidopsis [86]. CRISPR-Cas9 has also been used to alter $A L S$ in rice to confer herbicide resistance $[97,98]$ and both studies explored different strategies to enhance HDR in rice. In one study, plants with a lig4 mutation were shown to have between a 0.147 and $1 \%$ gene targeting efficiency and these contained biallelic mutations [98]. Lig4 is involved in the classic NHEJ pathway (Fig. 1a) and Lig4 mutants have been shown to undergo increased rates of HDR and microhomologybased alternative NHEJ in Arabidopsis [22]. In the second study, the authors observed high frequency HDR when using two gRNAs for cutting off the target gene and liberating donors that were provided in the form of both plasmids and free double-stranded DNAs [97].

For all HDR applications, efficiency will need to be improved. Increasing the efficiency of SSN delivery will greatly help genome editing, including HDR applications. If a higher percentage of plants or plant cells can receive SSNs, then more of them will have the potential to undergo HDR without increasing sample size. Although easy to use, agrobacterium-mediated delivery is not as efficient as ballistic bombardment because the latter can introduce multiple copies of donor DNA [93, 98]. One of the potential methods that may solve issues with difficult delivery, as well donor copy number, is geminivirus delivery. In tomatoes, geminiviruses replicons were found to create mutations at a 10 -fold higher frequency when compared to agrobacterium mediated transfer [94]. Recently, geminivirus systems were successfully used for CRISPR-Cas9 mediated HDR in rice [99] and wheat [100]. Alternatively, donor DNA may be liberated from integrated chromosome regions with an in-planta gene targeting strategy [86, 101]. The second issue to address is low occurrence of HDR in cells, especially in non-dividing cells. If all cells in culture or in planta were synchronized, then SSN and donor DNA could be introduced during replication which will boost HDR events. Cas9 nickases, with their ability to create single stand breaks (SSBs), have been utilized for HDR in Arabidopsis at high efficiencies and the authors have speculated the mechanism of HDR initiated by SSBs could be different from that of DSBs [85]. The mechanism of SSB based HDR, if discovered, should be useful for enhancing HDR. There are many exciting possibilities for HDR based genome editing, and innovative ideas will continue to further this area.

\section{TAL effector and CRISPR-Cas9 for transcriptional regulation}

Either a TAL effector or a deactivated Cas9 (dCas9) can be fused to an activator such as VP64 [102] or a repressor such as SRDX [103] for transcriptional regulation in plants (Fig. 6). There may be some differences intrinsic to TAL effector and Cas9 that make one more suitable for activating or repressing gene expression than the other. To date, no study has been carried out to make an accurate comparison of both systems in plants.

TAL effectors are natural transcriptional activators in plants $[104,105]$. This property was cleverly used for decoding the DNA recognition code of TAL repeats [25]. Although the endogenous transcriptional activation domain of a TAL effector seems potent for activation, it could be swapped with VP64 to make smaller proteins (Fig. 6a). TAL repeats, when fused to SRDX, repressed
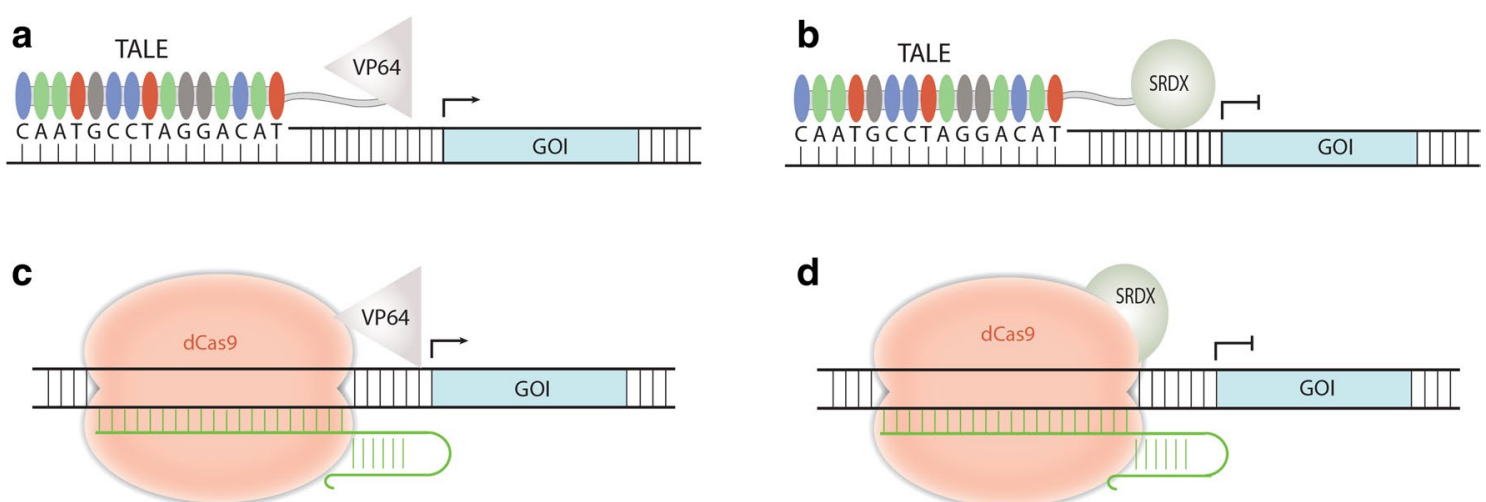

Fig. 6 TALE and CRISPR-Cas9 based transcriptome modulation systems. a The activator VP64 is fused to TALE for gene activation. b The repressor SRDX is fused to TALE for gene repression. c The activator VP64 is fused to dCas9 for gene activation. d The repressor SRDX is fused to dCas 99 for gene repression 
gene expression by more than twofold in Arabidopsis [106]. Interestingly, it was recently reported in Arabidopsis that binding of TAL proteins to the sense strand of a gene of interest is enough to result in gene repression [107], which is likely due to TAL proteins blocking transcription. Despite proven concept, there is almost no report on utilizing de novo-engineered TAL activators or repressors in plant research. This could be due to the difficulty of engineering of TAL proteins and multiplexing them in plant cells.

CRISPR-Cas9 may be more suitable for developing transcriptional regulation tools due to facile engineering and multiplexing. CRISPR-dCas9 based activators and repressors were demonstrated in transiently transformed tobacco [108] and in stably transformed Arabidopsis [81]. In the latter study, a tool kit was developed for easy assembly of a final T-DNA construct for simultaneous transcriptional modulation at multiple genetic loci in plants [81]. By targeting dCas9-VP64 to a highlymethylated promoter region, a 400 -fold increase in mRNA expression of the imprinted gene, AtFIS2, occurred in Arabidopsis rosette leaves [81]. The result demonstrated that methylated DNA, difficult to target with TAL proteins [109], is targetable by CRISPR-Cas9 (Table 1). Although these results are exciting, they merely represent the first generation of such activators and repressors. Further improvement of CRISPRdCas9 based transcriptional regulation systems for high efficiency in plants is anticipated.

\section{Future perspective}

CRISPR-Cas9 has been widely adopted for basic and applied research and as efficiency improves will continue as a popular tool. Currently, gene targets are somewhat limited by the NGG PAM site required by SpCas9 [38] (Table 1). However, target ranges will broaden as more systems are further explored. Orthogonal Cas9s have garnered attention for their unique PAM sites and gRNA structure, creating the possibility of expressing multiple Cas9s and gRNAs in a cell without interference. These orthogonal Cas9 variants differ in size and specificity as well as PAM sequences. Some of the most promising are NmCas9, StCas9 and SaCas9, all of which have been demonstrated in human cells [110] and the latter two in plants [111-114]. A CRISPR-Cpf1 system was reported in 2015 and it differs from the Cas9 system on several key parameters [115]. Cpf1 requires only a crRNA, making the gRNA 42 nt instead of 100 nt for Cas9. The Cpf1 PAM is TTTN and cleavage results in $5^{\prime}$ overhangs distall from protospacer elements. A shorter gRNA is easier to synthesize and an overhang may improve efficiency for NHEJ based gene insertion if the insert is designed with a complementary overhang. Lastly, the location of the DSB means that any indels will likely fail to disrupt the PAM site, leaving the possibility for multiple Cpf1 targeting events and allowing a second chance for gene insertion should the first attempt fail. Reports of Cpf1 in plants have also been published recently [116-121]. The CRISPR-Cpf1 system developed by Tang et al. achieved $100 \%$ mutagenesis frequency at all target sites in rice [119], demonstrating promising applications of Cpf1 in plants.

DNA independent delivery of SSNs for plant genome editing is another trend. Development of such methods are likely motivated for use in crop improvement in regards to regulation [2]. Nucleic-acid free delivery of TALEN has been successfully accomplished [122]. This study demonstrated that delivery of pure nuclease protein into protoplasts was possible albeit at a low frequency [122]. DNA-free delivery of Cas9 was accomplished by incubating Arabidopsis, rice, tobacco, and lettuce protoplasts with Cas9/gRNA ribonucleoprotein complexes [123]. Bread wheat was shown to be amenable to genome editing based on mRNA or ribonucleoprotein delivery of CRISPR-Cas9 [66, 124]. More recently, ribonucleoprotein delivery of CRISPR-Cpf1 was also demonstrated in soybean and wild tobacco protoplasts [120].

Genome editing may be achieved without introducing DNA DSBs. DNA base editing tools based on fusing cytidine deaminase to Cas9n or dCas9 were first demonstrated in human cells $[125,126]$. Encouragingly, this technology was recently shown to work in rice [127131], Arabidopsis [132], tomato [131], maize and wheat [129]. Without question, first generation base editing tools will be further expanded, improved and applied in many other plant species soon. Finally, as genome editing moves ahead into many crop plants, improving transformation and tissue culture methods will be critical for success. A recent report of using Baby boom and Wuschel genes to improve transformation efficiency in recalcitrant monocot plants set an exciting example of this endeavor [133].

\section{Abbreviations}

DSB: double strand break; NHEJ: non-homologous end joining; HDR: homology-directed repair; PAM: protospacer adjacent motif; ZFN: zinc-finger nuclease; TALE: transcription activator like effectors; CRISPR: clustered regularly interspaced palindromic repeats; Cas9: CRISPR associated protein 9; Cas9n: Cas9 nickase; dCas9: dead or deactivated Cas9; gRNA: guide RNA; Cpf1: CRISPR from Prevotella and Francisella 1; crRNA: CRISPR RNA; GOl: gene of interest.

\section{Authors' contributions}

AM and YQ wrote the manuscript draft. LL revised the manuscript. All authors read and approved the final manuscript.

\section{Author details}

${ }^{1}$ Department of Plant Science and Landscape Architecture, University of Maryland, College Park, MD 20742, USA. ${ }^{2}$ Department of Biology, East 
Carolina University, Greenville, NC 27858, USA. ${ }^{3}$ Institute for Bioscience and Biotechnology Research, University of Maryland, Rockville, MD 20850, USA.

\section{Acknowledgements}

Due to limited space, we couldn't cite the entirety of the related literature. We apologize to the authors whose studies were not cited in this review.

\section{Competing interests}

The authors declare that they have no competing interests.

\section{Funding}

This work is supported by a Collaborative Funding Grant from North Carolina Biotechnology Center and Syngenta Biotechnology (2016-CFG-8003) and a startup fund from University of Maryland-College Park to YQ.

\section{Publisher's Note}

Springer Nature remains neutral with regard to jurisdictional claims in published maps and institutional affiliations.

Received: 24 March 2017 Accepted: 19 April 2017 Published online: 24 April 2017

\section{References}

1. Ray DK, Mueller ND, West PC, Foley JA. Yield trends are insufficient to double global crop production by 2050. PLOS ONE. 2013;8(6):e66428.

2. Wolt JD, Wang K, Yang B. The Regulatory status of genome-edited crops. Plant Biotechnol J. 2016;14(2):510-8.

3. Kanaar R, Hoeijmakers JH, van Gent DC. Molecular mechanisms of DNA double strand break repair. Trends Cell Biol. 1998;8(12):483-9.

4. Steinert J, Schiml S, Puchta H. Homology-based double-strand break-induced genome engineering in plants. Plant Cell Rep. 2016;35(7):1429-38

5. Hartlerode AJ, Scully R. Mechanisms of double-strand break repair in somatic mammalian cells. Biochem J. 2009:423(2):157-68.

6. Pastwa E, Blasiak J. Non-homologous DNA end joining. Acta Biochim Pol. 2003:50(4):891-908.

7. Wang Y, Cheng X, Shan Q, Zhang Y, Liu J, Gao C, Qiu JL. Simultaneous editing of three homoeoalleles in hexaploid bread wheat confers heritable resistance to powdery mildew. Nat Biotechnol. 2014;32(9):947-51.

8. Puchta $\mathrm{H}$. The repair of double-strand breaks in plants: mechanisms and consequences for genome evolution. J Exp Bot. 2005;56(409):1-14.

9. Townsend JA, Wright DA, Winfrey RJ, Fu F, Maeder ML, Joung JK, Voytas DF. High-frequency modification of plant genes using engineered zincfinger nucleases. Nature. 2009;459(7245):442-5.

10. Paques F, Duchateau P. Meganucleases and DNA double-strand breakinduced recombination: perspectives for gene therapy. Curr Gene Ther. 2007;7(1):49-66.

11. Gao H, Smith J, Yang M, Jones S, Djukanovic V, Nicholson MG, West A, Bidney D, Falco SC, Jantz D, et al. Heritable targeted mutagenesis in maize using a designed endonuclease. Plant J. 2010;61(1):176-87.

12. Kim YG, Cha J, Chandrasegaran S. Hybrid restriction enzymes: zinc finger fusions to Fok I cleavage domain. Proc Natl Acad Sci USA 1996;93(3):1156-60.

13. Bibikova M, Carroll D, Segal DJ, Trautman JK, Smith J, Kim YG, Chandrasegaran S. Stimulation of homologous recombination through targeted cleavage by chimeric nucleases. Mol Cell Biol. 2001;21(1):289-97.

14. Beerli RR, Barbas CF 3rd. Engineering polydactyl zinc-finger transcription factors. Nat Biotechnol. 2002;20(2):135-41.

15. Segal DJ, Beerli RR, Blancafort P, Dreier B, Effertz K, Huber A, Koksch B, Lund CV, Magnenat L, Valente D, et al. Evaluation of a modular strategy for the construction of novel polydactyl zinc finger DNA-binding proteins. Biochemistry. 2003;42(7):2137-48.

16. Ramirez CL, Foley JE, Wright DA, Muller-Lerch F, Rahman SH, Cornu TI, Winfrey RJ, Sander JD, Fu F, Townsend JA, et al. Unexpected failure rates for modular assembly of engineered zinc fingers. Nat Methods. 2008;5(5):374-5.

17. Cornu TI, Thibodeau-Beganny S, Guhl E, Alwin S, Eichtinger M, Joung JK, Cathomen T. DNA-binding specificity is a major determinant of the activity and toxicity of zinc-finger nucleases. Mol Ther. 2008;16(2):352-8.

18. Doyon Y, McCammon JM, Miller JC, Faraji F, Ngo C, Katibah GE, Amora R, Hocking TD, Zhang L, Rebar EJ, et al. Heritable targeted gene disruption in zebrafish using designed zinc-finger nucleases. Nat Biotechnol. 2008;26(6):702-8.

19. Maeder ML, Thibodeau-Beganny S, Osiak A, Wright DA, Anthony RM, Eichtinger M, Jiang T, Foley JE, Winfrey RJ, Townsend JA, et al. Rapid "open-source" engineering of customized zinc-finger nucleases for highly efficient gene modification. Mol Cell. 2008;31(2):294-301.

20. Sander JD, Dahlborg EJ, Goodwin MJ, Cade L, Zhang F, Cifuentes D, Curtin SJ, Blackburn JS, Thibodeau-Beganny S, Qi Y, et al. Selection-free zinc-finger-nuclease engineering by context-dependent assembly (CoDA). Nat Methods. 2011;8(1):67-9.

21. Zhang F, Maeder ML, Unger-Wallace E, Hoshaw JP, Reyon D, Christian M, Li X, Pierick CJ, Dobbs D, Peterson T, et al. High frequency targeted mutagenesis in Arabidopsis thaliana using zinc finger nucleases. Proc Natl Acad Sci USA. 2010;107(26):12028-33.

22. Qi Y, Zhang Y, Zhang F, Baller JA, Cleland SC, Ryu Y, Starker CG, Voytas DF. Increasing frequencies of site-specific mutagenesis and gene targeting in Arabidopsis by manipulating DNA repair pathways. Genome Res. 2013:23(3):547-54.

23. Qi Y, Zhang Y, Baller JA, Voytas DF. Histone H2AX and the small RNA pathway modulate both non-homologous end-joining and homologous recombination in plants. Mutat Res. 2016;783:9-14.

24. Moscou MJ, Bogdanove AJ. A simple cipher governs DNA recognition by TAL effectors. Science. 2009;326(5959):1501.

25. Boch J, Scholze H, Schornack S, Landgraf A, Hahn S, Kay S, Lahaye T, Nickstadt A, Bonas U. Breaking the code of DNA binding specificity of TAL-type III effectors. Science. 2009;326(5959):1509-12.

26. Boch J, Bonas U. Xanthomonas AvrBs3 family-type III effectors: discovery and function. Annu Rev Phytopathol. 2010;48:419-36.

27. Christian M, Cermak T, Doyle EL, Schmidt C, Zhang F, Hummel A, Bogdanove AJ, Voytas DF. Targeting DNA double-strand breaks with TAL effector nucleases. Genetics. 2010;186(2):757-61.

28. Li T, Huang S, Jiang WZ, Wright D, Spalding MH, Weeks DP, Yang B. TAL nucleases (TALNs): hybrid proteins composed of TAL effectors and Fokl DNA-cleavage domain. Nucleic Acids Res. 2011;39(1):359-72.

29. Miller JC, Tan S, Qiao G, Barlow KA, Wang J, Xia DF, Meng X, Paschon DE, Leung E, Hinkley SJ, et al. A TALE nuclease architecture for efficient genome editing. Nat Biotechnol. 2011;29(2):143-8.

30. Mahfouz MM, Li L, Shamimuzzaman M, Wibowo A, Fang X, Zhu JK. De novo-engineered transcription activator-like effector (TALE) hybrid nuclease with novel DNA binding specificity creates double-strand breaks. Proc Natl Acad Sci USA. 2011;108(6):2623-8.

31. Cermak T, Doyle EL, Christian M, Wang L, Zhang Y, Schmidt C, Baller JA, Somia NV, Bogdanove AJ, Voytas DF. Efficient design and assembly of custom TALEN and other TAL effector-based constructs for DNA targeting. Nucleic Acids Res. 2011;39(12):e82.

32. Li T, Huang S, Zhao X, Wright DA, Carpenter S, Spalding MH, Weeks DP, Yang B. Modularly assembled designer TAL effector nucleases for targeted gene knockout and gene replacement in eukaryotes. Nucleic Acids Res. 2011;39(14):6315-25.

33. Morbitzer R, Elsaesser J, Hausner J, Lahaye T. Assembly of custom TALEtype DNA binding domains by modular cloning. Nucleic Acids Res. 2011;39(13):5790-9.

34. Wiedenheft B, Sternberg SH, Doudna JA. RNA-guided genetic silencing systems in bacteria and archaea. Nature. 2012;482(7385):331-8.

35. Barrangou R, Fremaux C, Deveau H, Richards M, Boyaval P, Moineau S, Romero DA, Horvath P. CRISPR provides acquired resistance against viruses in prokaryotes. Science. 2007;315(5819):1709-12.

36. Marraffini LA, Sontheimer EJ. CRISPR interference limits horizontal gene transfer in staphylococci by targeting DNA. Science. 2008;322(5909):1843-5. 
37. Makarova KS, Zhang F, Koonin EV. SnapShot: Class 2 CRISPR-Cas systems. Cell. 2017;168(1-2):328.

38. Jinek M, Chylinski K, Fonfara I, Hauer M, Doudna JA, Charpentier E. A programmable dual-RNA-guided DNA endonuclease in adaptive bacterial immunity. Science. 2012;337(6096):816-21.

39. Cong L, Ran FA, Cox D, Lin S, Barretto R, Habib N, Hsu PD, Wu X, Jiang W, Marraffini LA, et al. Multiplex genome engineering using CRISPR/Cas systems. Science. 2013;339(6121):819-23.

40. Mali P, Yang L, Esvelt KM, Aach J, Guell M, DiCarlo JE, Norville JE, Church GM. RNA-guided human genome engineering via Cas9. Science. 2013:339(6121):823-6.

41. Paul JW 3rd, Qi Y. CRISPR/Cas9 for plant genome editing: accomplishments, problems and prospects. Plant Cell Rep. 2016;35(7):1417-27.

42. Lowder L, Malzahn A, Qi Y. Rapid evolution of manifold CRISPR systems for plant genome editing. Front Plant Sci. 2016;7:1683.

43. Zhang Y, Zhang F, Li X, Baller JA, Qi Y, Starker CG, Bogdanove AJ, Voytas DF. Transcription activator-like effector nucleases enable efficient plant genome engineering. Plant Physiol. 2013;161(1):20-7.

44. Christian M, Qi Y, Zhang Y, Voytas DF. Targeted mutagenesis of Arabidopsis thaliana using engineered TAL effector nucleases. G3 (Bethesda). 2013;3(10):1697-705.

45. Lor VS, Starker CG, Voytas DF, Weiss D, Olszewski NE. Targeted mutagenesis of the tomato PROCERA gene using TALENs. Plant Physiol. 2014;166:1288-91.

46. Shan Q, Wang Y, Chen K, Liang Z, Li J, Zhang Y, Zhang K, Liu J, Voytas $D F$, Zheng $X$, et al. Rapid and efficient gene modification in rice and Brachypodium using TALENs. Mol Plant. 2013;6(4):1365-8.

47. Zhang H, Gou F, Zhang J, Liu W, Li Q, Mao Y, Botella JR, Zhu JK. TALENmediated targeted mutagenesis produces a large variety of heritable mutations in rice. Plant Biotechnol J. 2016;14(1):186-94.

48. Li T, Liu B, Spalding MH, Weeks DP, Yang B. High-efficiency TALENbased gene editing produces disease-resistant rice. Nat Biotechnol. 2012;30(5):390-2

49. Haun W, Coffman A, Clasen BM, Demorest ZL, Lowy A, Ray E, Retterath A, Stoddard T, Juillerat A, Cedrone F, et al. Improved soybean oil quality by targeted mutagenesis of the fatty acid desaturase 2 gene family. Plant Biotechnol J. 2014;12(7):934-40.

50. Shan Q, Zhang Y, Chen K, Zhang K, Gao C. Creation of fragrant rice by targeted knockout of the OsBADH2 gene using TALEN technology. Plant Biotechnol J. 2015;13(6):791-800.

51. Ma L, Zhu F, Li Z, Zhang J, Li X, Dong J, Wang T. TALEN-based mutagenesis of lipoxygenase LOX3 enhances the storage tolerance of rice (Oryza sativa) seeds. PLoS ONE. 2015;10(12):e0143877.

52. Clasen BM, Stoddard TJ, Luo S, Demorest ZL, Li J, Cedrone F, Tibebu R, Davison S, Ray EE, Daulhac A, et al. Improving cold storage and processing traits in potato through targeted gene knockout. Plant Biotechnol J. 2016;14(1):169-76.

53. Li M, Li X, Zhou Z, Wu P, Fang M, Pan X, Lin Q, Luo W, Wu G, Li H. Reassessment of the four yield-related genes Gn1a, DEP1, GS3, and IPA1 in rice using a CRISPR/Cas9 system. Front Plant Sci. 2016;7:377.

54. Li Q, Zhang D, Chen M, Liang W, Wei J, Qi Y, Yuan Z. Development of japonica photo-sensitive genic male sterile rice lines by editing carbon starved anther using CRISPR/Cas9. J Genet Genom. 2016;43:415-9.

55. Zhou H, He M, Li J, Chen L, Huang Z, Zheng S, Zhu L, Ni E, Jiang D, Zhao $B$, et al. Development of commercial thermo-sensitive genic male sterile rice accelerates hybrid rice breeding using the CRISPR/Cas9mediated TMS5 editing system. Sci Rep. 2016;6:37395.

56. Wang F, Wang C, Liu P, Lei C, Hao W, Gao Y, Liu YG, Zhao K. Enhanced rice blast resistance by CRISPR/Cas9-targeted mutagenesis of the ERF transcription factor gene OsERF922. PLoS ONE. 2016;11(4):e0154027.

57. Pyott DE, Sheehan E, Molnar A. Engineering of CRISPR/Cas9-mediated potyvirus resistance in transgene-free Arabidopsis plants. Mol Plant Pathol. 2016;17:1276-88.

58. Baltes N. Conferring resistance to geminiviruses with the CRISPR-Cas prokaryotic immune system. Nat Plants. 2015;1:15145

59. Gutierrez C. Geminivirus DNA replication. Cell Mol Life Sci. 1999;56(3-4):313-29.

60. Ali Z, Abul-faraj A, Li L, Ghosh N, Piatek M, Mahjoub A, Aouida M, Piatek A, Baltes NJ, Voytas DF, et al. Efficient virus-mediated genome editing in plants using the CRISPR/Cas9 system. Mol Plant. 2015;8(8):1288-91.
61. Ji X, Zhang H, Zhang Y, Wang Y, Gao C. Establishing a CRISPR-Cas-like immune system conferring DNA virus resistance in plants. Nat Plants. 2015;1:15144.

62. Zhang Y, Rajan R, Seifert HS, Mondragon A, Sontheimer EJ. DNase H activity of Neisseria meningitidis Cas9. Mol Cell. 2015;60(2):242-55.

63. Zhao C, Zhang Z, Xie S, Si T, Li Y, Zhu JK. Mutational evidence for the critical role of CBF genes in cold acclimation in Arabidopsis. Plant Physiol. 2016;171:2744-59.

64. Zhou X, Jacobs TB, Xue LJ, Harding SA, Tsai CJ. Exploiting SNPs for biallelic CRISPR mutations in the outcrossing woody perennial Populus reveals 4-coumarate:CoA ligase specificity and redundancy. New Phytol. 2015;208(2):298-301.

65. Shan Q, Wang Y, Li J, Zhang Y, Chen K, Liang Z, Zhang K, Liu J, Xi JJ, Qiu $J \mathrm{~L}$, et al. Targeted genome modification of crop plants using a CRISPRCas system. Nat Biotechnol. 2013;31(8):686-8.

66. Zhang Y, Liang Z, Zong Y, Wang Y, Liu J, Chen K, Qiu JL, Gao C. Efficient and transgene-free genome editing in wheat through transient expression of CRISPR/Cas9 DNA or RNA. Nat Commun. 2016;7:12617.

67. Li C, Unver T, Zhang B. A high-efficiency CRISPR/Cas9 system for targeted mutagenesis in cotton (Gossypium hirsutum L.). Sci Rep. 2017;7:43902

68. Chen X, Lu X, Shu N, Wang S, Wang J, Wang D, Guo L, Ye W. Targeted mutagenesis in cotton (Gossypium hirsutum L.) using the CRISPR/Cas9 system. Sci Rep. 2017;7:44304.

69. Morineau C, Bellec Y, Tellier F, Gissot L, Kelemen Z, Nogue F, Faure JD. Selective gene dosage by CRISPR-Cas9 genome editing in hexaploid Camelina sativa. Plant Biotechnol J. 2016. doi:10.1111/pbi.12671.

70. Jiang WZ, Henry IM, Lynagh PG, Comai L, Cahoon EB, Weeks DP. Significant enhancement of fatty acid composition in seeds of the allohexaploid, Camelina sativa, using CRISPR/Cas9 gene editing. Plant Biotechnol J. 2016. doi:10.1111/pbi.12663.

71. Gao Y, Zhang Y, Zhang D, Dai X, Estelle M, Zhao Y. Auxin binding protein 1 (ABP1) is not required for either auxin signaling or Arabidopsis development. Proc Natl Acad Sci USA. 2015;112(7):2275-80.

72. Tang F, Yang S, Liu J, Zhu H. Rj4, a gene controlling nodulation specificity in soybeans, encodes a thaumatin-like protein but not the one previously reported. Plant Physiol. 2016;170(1):26-32.

73. Schwab R, Palatnik JF, Riester M, Schommer C, Schmid M, Weigel D. Specific effects of microRNAs on the plant transcriptome. Dev Cell. 2005:8(4):517-27.

74. Liu X, Hao L, Li D, Zhu L, Hu S. Long non-coding RNAs and their biological roles in plants. Genom Proteom Bioinform. 2015;13(3):137-47.

75. Basak J, Nithin C. Targeting non-coding RNAs in plants with the CRISPRCas technology is a challenge yet worth accepting. Front Plant Sci. 1001;2015:6.

76. Zhou H, Liu B, Weeks DP, Spalding MH, Yang B. Large chromosomal deletions and heritable small genetic changes induced by CRISPR/Cas9 in rice. Nucleic Acids Res. 2014;42(17):10903-14.

77. Zhao Y, Zhang C, Liu W, Gao W, Liu C, Song G, Li WX, Mao L, Chen B, Xu $Y$, et al. An alternative strategy for targeted gene replacement in plants using a dual-sgRNA/Cas9 design. Sci Rep. 2016;6:23890.

78. Duan YB, Li J, Qin RY, Xu RF, Li H, Yang YC, Ma H, Li L, Wei PC, Yang JB. Identification of a regulatory element responsible for salt induction of rice OsRAV2 through ex situ and in situ promoter analysis. Plant Mol Biol. 2016;90(1-2):49-62.

79. Xing HL, Dong L, Wang ZP, Zhang HY, Han CY, Liu B, Wang XC, Chen QJ. A CRISPR/Cas9 toolkit for multiplex genome editing in plants. BMC Plant Biol. 2014;14:327.

80. Ma X, Zhang Q, Zhu Q, Liu W, Chen Y, Qiu R, Wang B, Yang Z, Li H, Lin $Y$, et al. A robust CRISPR/Cas9 system for convenient, high-efficiency multiplex genome editing in monocot and dicot plants. Mol Plant. 2015;8(8):1274-84.

81. Lowder LG, Zhang D, Baltes NJ, Paul JW, Tang X, Zheng X, Voytas DF, Hsieh TF, Zhang Y, Qi Y. A CRISPR/Cas9 toolbox for multiplexed plant genome editing and transcriptional regulation. Plant Physiol. 2015;169:971-85.

82. Zhang Z, Mao Y, Ha S, Liu W, Botella JR, Zhu JK. A multiplex CRISPR/Cas9 platform for fast and efficient editing of multiple genes in Arabidopsis. Plant Cell Rep. 2016;35(7):1519-33. 
83. Wang C, Shen L, Fu Y, Yan C, Wang K. A simple CRISPR/Cas9 system for multiplex genome editing in rice. J Genet Genom. 2015:42(12):703-6.

84. Ran FA, Hsu PD, Lin CY, Gootenberg JS, Konermann S, Trevino AE, Scott DA, Inoue A, Matoba S, Zhang Y, et al. Double nicking by RNAguided CRISPR Cas9 for enhanced genome editing specificity. Cell. 2013;154(6):1380-9.

85. Fauser F, Schiml S, Puchta H. Both CRISPR/Cas-based nucleases and nickases can be used efficiently for genome engineering in Arabidopsis thaliana. Plant J. 2014;79(2):348-59.

86. Schiml S, Fauser F, Puchta H. The CRISPR/Cas system can be used as nuclease for in planta gene targeting and as paired nickases for directed mutagenesis in Arabidopsis resulting in heritable progeny. Plant J. 2014;80(6):1139-50.

87. Mikami M, Toki S, Endo M. Precision targeted mutagenesis via Cas9 paired nickases in rice. Plant Cell Physiol. 2016;57(5):1058-68.

88. Tang X, Zheng X, Qi Y, Zhang D, Cheng Y, Tang A, Voytas DF, Zhang Y. A single transcript CRISPR-Cas9 system for efficient genome editing in plants. Mol Plant. 2016;9(7):1088-91

89. Tsai SQ, Wyvekens N, Khayter C, Foden JA, Thapar V, Reyon D, Goodwin MJ, Aryee MJ, Joung JK. Dimeric CRISPR RNA-guided FokI nucleases for highly specific genome editing. Nat Biotechnol. 2014;32(6):569-76.

90. Guilinger JP, Thompson DB, Liu DR. Fusion of catalytically inactive Cas9 to Fokl nuclease improves the specificity of genome modification. Nat Biotechnol. 2014;32(6):577-82

91. Hockemeyer D, Wang H, Kiani S, Lai CS, Gao Q, Cassady JP, Cost GJ, Zhang L, Santiago Y, Miller JC, et al. Genetic engineering of human pluripotent cells using TALE nucleases. Nat Biotechnol. 2011:29(8):731-4

92. Budhagatapalli N, Rutten T, Gurushidze M, Kumlehn J, Hensel G. Targeted modification of gene function exploiting homologydirected repair of TALEN-mediated double-strand breaks in barley. G3 (Bethesda). 2015:5(9):1857-63.

93. Li T, Liu B, Chen CY, Yang B. TALEN-mediated homologous recombination produces site-directed DNA base change and herbicide-resistant rice. J Genet Genom. 2016;43(5):297-305.

94. Cermak T, Baltes NJ, Cegan R, Zhang Y, Voytas DF. High-frequency, precise modification of the tomato genome. Genome Biol. 2015;16(1):232.

95. Baltes NJ, Gil-Humanes J, CermakT, Atkins PA, Voytas DF. DNA replicons for plant genome engineering. Plant Cell. 2014;26(1):151-63.

96. Li JF, Norville JE, Aach J, McCormack M, Zhang D, Bush J, Church GM, Sheen J. Multiplex and homologous recombination-mediated genome editing in Arabidopsis and Nicotiana benthamiana using guide RNA and Cas9. Nat Biotechnol. 2013:31(8):688-91.

97. Sun Y, Zhang X, Wu C, He Y, Ma Y, Hou H, Guo X, Du W, Zhao Y, Xia L. Engineering herbicide resistant rice plants through CRISPR/Cas9-mediated homologous recombination of the acetolactate synthase. Mol Plant. 2016;9(4):628-31.

98. Endo M, Mikami M, Toki S. Biallelic gene targeting in rice. Plant Physiol. 2016;170(2):667-77

99. Wang M, Lu Y, Botella J, Mao Y, Hua K, Zhu JK. Gene Targeting by Homology-directed Repair in Rice using a Geminivirus-based CRISPR/ Cas9 System. Mol Plant. 2017. doi:10.1016/j.molp.2017.03.002.

100. Gil-Humanes J, Wang Y, Liang Z, Shan Q, Ozuna CV, Sanchez-Leon S, Baltes NJ, Starker C, Barro F, Gao C, et al. High-efficiency gene targeting in hexaploid wheat using DNA replicons and CRISPR/Cas9. Plant J. 2017:89(6):1251-62

101. Fauser F, Roth N, Pacher M, Ilg G, Sanchez-Fernandez R, Biesgen C, Puchta $\mathrm{H}$. In planta gene targeting. Proc Natl Acad Sci USA 2012;109(19):7535-40.

102. Beerli RR, Segal DJ, Dreier B, Barbas CF 3rd. Toward controlling gene expression at will: specific regulation of the erbB-2/HER-2 promoter by using polydactyl zinc finger proteins constructed from modular build ing blocks. Proc Natl Acad Sci USA. 1998;95(25):14628-33.

103. Hiratsu K, Matsui K, Koyama T, Ohme-Takagi M. Dominant repression of target genes by chimeric repressors that include the EAR motif, a repression domain, in Arabidopsis. Plant J. 2003;34(5):733-9.

104. Kay S, Hahn S, Marois E, Hause G, Bonas U. A bacterial effector acts as a plant transcription factor and induces a cell size regulator. Science. 2007;318(5850):648-51.
105. Romer P, Hahn S, Jordan T, Strauss T, Bonas U, Lahaye T. Plant pathogen recognition mediated by promoter activation of the pepper Bs3 resistance gene. Science. 2007;318(5850):645-8

106. Mahfouz MM, Li L, Piatek M, Fang X, Mansour H, Bangarusamy DK, Zhu JK. Targeted transcriptional repression using a chimeric TALE-SRDX repressor protein. Plant Mol Biol. 2012;78(3):311-21.

107. Lin S, Zhao Y, Zhu Y, Gosney M, Deng X, Wang X, Lin J. An effective and inducible system of TAL effector-mediated transcriptional repression in Arabidopsis. Mol Plant. 2016:9(11):1546-9.

108. Piatek A, Ali Z, Baazim H, Li L, Abulfaraj A, Al-Shareef S, Aouida M, Mahfouz MM. RNA-guided transcriptional regulation in planta via synthetic dCas9-based transcription factors. Plant Biotechnol J. 2015;13(4):57889. doi:10.1111/pbi.12284

109. Valton J, Dupuy A, Daboussi F, Thomas S, Marechal A, Macmaster R, Melliand K, Juillerat A, Duchateau P. Overcoming transcription activator-like effector (TALE) DNA binding domain sensitivity to cytosine methylation. J Biol Chem. 2012;287(46):38427-32.

110. Esvelt KM, Mali P, Braff JL, Moosburner M, Yaung SJ, Church GM. Orthogonal Cas9 proteins for RNA-guided gene regulation and editing. Nat Methods. 2013;10(11):1116-21.

111. Steinert J, Schiml S, Fauser F, Puchta H. Highly efficient heritable plant genome engineering using Cas9 orthologues from Streptococcus thermophilus and Staphylococcus aureus. Plant J. 2015;84(6):1295-305.

112. Kaya H, Mikami M, Endo A, Endo M, Toki S. Highly specific targeted mutagenesis in plants using Staphylococcus aureus Cas9. Sci Rep. 2016:6:26871.

113. Zhang HY, Wang $X H$, Dong L, Wang ZP, Liu B, LV J, Xing HL, Han CY, Wang XC, Chen QJ. MISSA 2.0: an updated synthetic biology toolbox for assembly of orthogonal CRISPR/Cas systems. Sci Rep. 2017:7:41993.

114. Kaya H, Ishibashi K, Toki S. A split Staphylococcus aureus Cas 9 as a compact genome editing tool in plants. Plant Cell Physiol. 2017. doi:10.1093/pcp/pcx034.

115. Zetsche B, Gootenberg JS, Abudayyeh OO, Slaymaker IM, Makarova KS, Essletzbichler P, Volz SE, Joung J, van der Oost J, Regev A, et al. Cpf1 is a single RNA-guided endonuclease of a class 2 CRISPR-Cas system. Cell. 2015;163(3):759-71.

116. Yin X, Biswal AK, Dionora J, Perdigon KM, Balahadia CP, Mazumdar S, Chater C, Lin HC, Coe RA, Kretzschmar T et al. CRISPR-Cas9 and CRISPRCpf1 mediated targeting of a stomatal developmental gene EPFL9 in rice. Plant Cell Rep. 2017. doi:10.1007/s00299-017-2118-z.

117. Xu R, Qin R, Li H, Li D, Li L, Wei P, Yang J. Generation of targeted mutant rice using a CRISPR-Cpf1 system. Plant Biotechnol J. 2016. doi:10.1111/ pbi.12669.

118. Endo A, Masafumi M, Kaya H, Toki S. Efficient targeted mutagenesis of rice and tobacco genomes using Cpf1 from Francisella novicida. Sci Rep. 2016:6:38169. doi:10.1038/srep38169

119. Tang X, Lowder LG, Zhang T, Malzahn AA, Zheng X, Voytas DF, Zhong Z, Chen Y, Ren Q, Li Q, et al. A CRISPR-Cpf1 system for efficient genome editing and transcriptional repression in plants. Nat Plants. 2017:3:17018.

120. Kim H, Kim ST, Ryu J, Kang BC, Kim JS, Kim SG. CRISPR/Cpf1-mediated DNA-free plant genome editing. Nat Commun. 2017;8:14406 doi:10.1038/ncomms14406.

121. Wang M, Mao Y, Lu Y, Tao X, Zhu JK. Multiplex gene editing in rice using the CRISPR-Cpf1 System. Mol Plant. 2017. doi:10.1016/j. molp.2017.03.001.

122. Luo S, Li J, Stoddard TJ, Baltes NJ, Demorest ZL, Clasen BM, Coffman A, Retterath A, Mathis L, Voytas DF, et al. Non-transgenic plant genome editing using purified sequence-specific nucleases. Mol Plant. 2015:8(9):1425-7.

123. Woo JW, Kim J, Kwon SI, Corvalan C, Cho SW, Kim H, Kim SG, Kim ST, Choe S, Kim JS. DNA-free genome editing in plants with preassembled CRISPR-Cas9 ribonucleoproteins. Nat Biotechnol. 2015;33(11):1162-4.

124. Liang Z, Chen K, Li T, Zhang Y, Wang Y, Zhao Q, Liu J, Zhang H, Liu C, Ran Y, et al. Efficient DNA-free genome editing of bread wheat using CRISPR/Cas9 ribonucleoprotein complexes. Nat Commun. 2017:8:14261.

125. Komor AC, Kim YB, Packer MS, Zuris JA, Liu DR. Programmable editing of a target base in genomic DNA without double-stranded DNA cleavage. Nature. 2016:533(7603):420-4 
126. Nishida K, Arazoe T, Yachie N, Banno S, Kakimoto M, Tabata M, Mochizuki M, Miyabe A, Araki M, Hara KY, et al. Targeted nucleotide editing using hybrid prokaryotic and vertebrate adaptive immune systems. Science. 2016;353(6305):8729.

127. Li J, Sun Y, Du J, Zhao Y, Xia L. Generation of targeted point mutations in rice by a modified CRISPR/Cas9 system. Mol Plant. 2016;10(3):526-9.

128. LuY, Zhu JK. Precise editing of a target base in the rice genome using a modified CRISPR/Cas9 System. Mol Plant. 2016;10(3):523-5.

129. Zong Y, Wang Y, Li C, Zhang R, Chen K, Ran Y, Qiu JL, Wang D, Gao C. Precise base editing in rice, wheat and maize with a Cas9- cytidine deaminase fusion. Nat Biotechnol. 2017. doi:10.1038/nbt.3811.

130. Ren B, Yan F, Kuang Y, Li N, Zhang D, Lin H, Zhou H. A CRISPR/Cas9 toolkit for efficient targeted base editing to induce genetic variations in rice. Sci China Life Sci. 2017. doi:10.1007/s11427-016-0406-x.

131. Shimatani Z, Kashojiya S, Takayama M, Terada R, Arazoe T, Ishii H, Teramura H, Yamamoto T, Komatsu H, Miura K et al. Targeted base editing in rice and tomato using a CRISPR-Cas9 cytidine deaminase fusion. Nat Biotechnol. 2017. doi:10.1038/nbt.3833.

132. Chen Y, Wang Z, Ni H, Xu Y, Chen Q, Jiang L. CRISPR/Cas9-mediated base-editing system efficiently generates gain-of-function mutations in Arabidopsis. Sci China Life Sci. 2017. doi:10.1007/s11427-017-9021-5.

133. Lowe K, Wu E, Wang N, Hoerster G, Hastings C, Cho MJ, Scelonge C, Lenderts B, Chamberlin M, Cushatt J et al. Morphogenic regulators baby boom and wuschel improve monocot transformation. Plant Cell. 2016. doi:10.1105/tpc.16.00124.

134. Forner J, Pfeiffer A, Langenecker T, Manavella PA, Lohmann JU. Germline-transmitted genome editing in Arabidopsis thaliana using TAL-effector-nucleases. PLoS ONE. 2015;10(3):e0121056.

135. Johnson RA, Gurevich V, Levy AA. A rapid assay to quantify the cleavage efficiency of custom-designed nucleases in planta. Plant Mol Biol. 2013;82(3):207-21.

136. Wendt T, Holm PB, Starker CG, Christian M, Voytas DF, Brinch-Pedersen $\mathrm{H}$, Holme IB. TAL effector nucleases induce mutations at a pre-selected location in the genome of primary barley transformants. Plant Mol Biol. 2013;83(3):279-85.

137. Gurushidze M, Hensel G, Hiekel S, Schedel S, Valkov V, Kumlehn J. True-breeding targeted gene knock-out in barley using designer TALEnuclease in haploid cells. PLoS ONE. 2014;9(3):e92046.

138. Char SN, Unger-Wallace E, Frame B, Briggs SA, Main M, Spalding MH, Vollbrecht E, Wang K, Yang B. Heritable site-specific mutagenesis using TALENs in maize. Plant Biotechnol J. 2015;13(7):1002-10.

139. Liang Z, Zhang K, Chen K, Gao C. Targeted mutagenesis in Zea mays using TALENs and the CRISPR/Cas system. J Genet Genom. 2014;41(2):63-8.

140. Li J, Stoddard TJ, Demorest ZL, Lavoie PO, Luo S, Clasen BM, Cedrone F, Ray EE, Coffman AP, Daulhac A, et al. Multiplexed, targeted gene editing in Nicotiana benthamiana for glyco-engineering and monoclonal antibody production. Plant Biotechnol J. 2016;14(2):533-42.

141. Nicolia A, Proux-Wera E, Ahman I, Onkokesung N, Andersson M, Andreasson E, Zhu LH. Targeted gene mutation in tetraploid potato through transient TALEN expression in protoplasts. J Biotechnol. 2015;204:17-24

142. Butler NM, Baltes NJ, Voytas DF, Douches DS. Geminivirus-mediated genome editing in potato (Solanum tuberosum L.) using sequencespecific nucleases. Front Plant Sci. 1045;2016:7.

143. Wang M, Liu Y, Zhang C, Liu J, Liu X, Wang L, Wang W, Chen H, Wei C, Ye $X$, et al. Gene editing by co-transformation of TALEN and chimeric RNA/ DNA oligonucleotides on the rice OsEPSPS gene and the inheritance of mutations. PLOS ONE. 2015;10(4):e0122755.

144. Blanvillain-Baufume S, Reschke M, Sole M, Auguy F, Doucoure H, Szurek B, Meynard D, Portefaix M, Cunnac S, Guiderdoni E et al. Targeted promoter editing for rice resistance to Xanthomonas oryzae pv. oryzae reveals differential activities for SWEET14-inducing TAL effectors. Plant Biotechnol J. 2017;15(3):306-17. doi:10.1111/pbi.12613.

145. Nishizawa-Yokoi A, Cermak T, Hoshino T, Sugimoto K, Saika H, Mori A, Osakabe K, Hamada M, Katayose Y, Starker C, et al. A defect in DNA Ligase4 enhances the frequency of TALEN-mediated targeted mutagenesis in rice. Plant Physiol. 2016;170(2):653-66.

146. Demorest ZL, Coffman A, Baltes NJ, Stoddard TJ, Clasen BM, Luo S, Retterath A, Yabandith A, Gamo ME, Bissen J, et al. Direct stacking of sequence-specific nuclease-induced mutations to produce high oleic and low linolenic soybean oil. BMC Plant Biol. 2016;16(1):225.

147. Du H, Zeng X, Zhao M, Cui X, Wang Q, Yang H, Cheng H, Yu D. Efficient targeted mutagenesis in soybean by TALENs and CRISPR/Cas9. J Biotechnol. 2016;217:90-7.

148. Jung JH, Altpeter F. TALEN mediated targeted mutagenesis of the caffeic acid O-methyltransferase in highly polyploid sugarcane improves cell wall composition for production of bioethanol. Plant Mol Biol. 2016;92(1-2):131-42.

149. Feng Z, Zhang B, Ding W, Liu X, Yang DL, Wei P, Cao F, Zhu S, Zhang $F$, Mao Y, et al. Efficient genome editing in plants using a CRISPR/Cas system. Cell Res. 2013;23(10):1229-32.

150. Feng Z, Mao Y, Xu N, Zhang B, Wei P, Yang DL, Wang Z, Zhang Z, Zheng $R$, Yang $L$, et al. Multigeneration analysis reveals the inheritance, specificity, and patterns of CRISPR/Cas-induced gene modifications in Arabidopsis. Proc Natl Acad Sci USA. 2014;111(12):4632-7.

151. Mao Y, Zhang H, Xu N, Zhang B, Gou F, Zhu JK. Application of the CRISPR-Cas system for efficient genome engineering in plants. Mol Plant. 2013;6(6):2008-11.

152. Mao Y, Zhang Z, Feng Z, Wei P, Zhang H, Botella JR, Zhu JK. Development of germ-line-specific CRISPR-Cas9 systems to improve the production of heritable gene modifications in Arabidopsis. Plant Biotechnol J. 2015;14(2):519-32.

153. Jiang W, Zhou H, Bi H, Fromm M, Yang B, Weeks DP. Demonstration of CRISPR/Cas9/sgRNA-mediated targeted gene modification in Arabidopsis, tobacco, sorghum and rice. Nucleic Acids Res. 2013;41(20):e188.

154. Jiang W, Yang B, Weeks DP. Efficient CRISPR/Cas9-mediated gene editing in Arabidopsis thaliana and inheritance of modified genes in the T2 and T3 generations. PLOS ONE. 2014;9(6):e99225.

155. Hyun Y, Kim J, Cho SW, Choi Y, Kim JS, Coupland G. Site-directed mutagenesis in Arabidopsis thaliana using dividing tissue-targeted RGEN of the CRISPR/Cas system to generate heritable null alleles. Planta. 2015;241(1):271-84.

156. Johnson RA, Gurevich V, Filler S, Samach A, Levy AA. Comparative assessments of CRISPR-Cas nucleases' cleavage efficiency in planta. Plant Mol Biol. 2015;87(1-2):143-56.

157. Wang ZP, Xing HL, Dong L, Zhang HY, Han CY, Wang XC, Chen QJ. Egg cell-specific promoter-controlled CRISPR/Cas9 efficiently generates homozygous mutants for multiple target genes in Arabidopsis in a single generation. Genome Biol. 2015;16:144.

158. Yan L, Wei S, Wu Y, Hu R, Li H, Yang W, Xie Q. High-efficiency genome editing in Arabidopsis using YAO promoter-driven CRISPR/Cas9 system. Mol Plant. 2015;8(12):1820-3.

159. Kim H, Kim ST, Ryu J, Choi MK, Kweon J, Kang BC, Ahn HM, Bae S, Kim JS, Kim SG. A simple, flexible and high-throughput cloning system for plant genome editing via CRISPR-Cas system. J Integr Plant Biol. 2016;58:705-12.

160. Jia $Y$, Ding $Y$, Shi $Y$, Zhang $X$, Gong Z, Yang S. The cbfs triple mutants reveal the essential functions of CBFs in cold acclimation and allow the definition of CBF regulons in Arabidopsis. New Phytol. 2016;212(2):345-53.

161. Ordon J, Gantner J, Kemna J, Schwalgun L, Reschke M, Streubel J, Boch J, Stuttmann J. Generation of chromosomal deletions in dicotyledonous plants employing a user-friendly genome editing toolkit. Plant J. 2017:89(1):155-68.

162. Li P, Li YJ, Zhang FJ, Zhang GZ, Jiang XY, Yu HM, Hou BK. The Arabidopsis UDP-glycosyltransferases UGT79B2 and 79B3, contribute to cold, salt and drought stress tolerance via modulating anthocyanin accumulation. Plant J. 2017;89(1):85-103.

163. Veillet F, Gaillard C, Coutos-Thevenot P, La Camera S. Targeting the AtCWIN1 Gene to explore the role of invertases in sucrose transport in roots and during Botrytis cinerea infection. Front Plant Sci. 1899;2016:7.

164. Ryder P, McHale M, Fort A, Spillane C. Generation of stable nulliplex autopolyploid lines of Arabidopsis thaliana using CRISPR/Cas9 genome editing. Plant Cell Rep. 2017. doi:10.1007/s00299-017-2125-0.

165. Lawrenson T, Shorinola O, Stacey N, Li C, Ostergaard L, Patron N, Uauy C, Harwood W. Induction of targeted, heritable mutations in barley and Brassica oleracea using RNA-guided Cas9 nuclease. Genome Biol. 2015;16:258. 
166. Baek K, Kim DH, Jeong J, Sim SJ, Melis A, Kim JS, Jin E, Bae S. DNA-free two-gene knockout in Chlamydomonas reinhardtii via CRISPR-Cas9 ribonucleoproteins. Sci Rep. 2016;6:30620.

167. Janga MR, Campbell LM, Rathore KS. CRISPR/Cas9-mediated targeted mutagenesis in upland cotton (Gossypium hirsutum L.). Plant Mol Biol. 2017. doi:10.1007/s11103-017-0599-3.

168. laffaldano B, Zhang Y, Cornish K. CRISPR/Cas9 genome editing of rubber producing dandelion Taraxacum kok-saghyz using Agrobacterium rhizogenes without selection. Ind Crops Prod. 2016;89:356-62.

169. Sauer NJ, Narvaez-Vasquez J, Mozoruk J, Miller RB, Warburg ZJ, Woodward MJ, Mihiret YA, Lincoln TA, Segami RE, Sanders SL, et al. Oligonucleotide-mediated genome editing provides precision and function to engineered nucleases and antibiotics in plants. Plant Physiol. 2016;170(4):1917-28.

170. Ren C, Liu X, Zhang Z, Wang Y, Duan W, Li S, Liang Z. CRISPR/Cas9-mediated efficient targeted mutagenesis in Chardonnay (Vitis vinifera L.). Sci Rep. 2016;6:32289.

171. Sugano SS, Shirakawa M, Takagi J, Matsuda Y, Shimada T, HaraNishimura I, Kohchi T. CRISPR/Cas9-mediated targeted mutagenesis in the liverwort Marchantia polymorpha L. Plant Cell Physiol. 2014;55(3):475-81.

172. Wang L, Wang L, Tan Q, Fan Q, Zhu H, Hong Z, Zhang Z, Duanmu D. Efficient inactivation of symbiotic nitrogen fixation related genes in Lotus japonicus using CRISPR-Cas9. Front Plant Sci. 2016;7:1333.

173. Svitashev S, Young JK, Schwartz C, Gao H, Falco SC, Cigan AM. Targeted Mutagenesis, precise gene editing, and site-specific gene insertion in maize using Cas9 and guide RNA. Plant Physiol. 2015;169(2):931-45.

174. Zhu J, Song N, Sun S, Yang W, Zhao H, Song W, Lai J. Efficiency and inheritance of targeted mutagenesis in maize using CRISPR-Cas9. J Genet Genom. 2016;43(1):25-36

175. Feng C, Yuan J, Wang R, Liu Y, Birchler JA, Han F. Efficient targeted genome modification in maize using CRISPR/Cas9 system. J Genet Genom. 2016:43(1):37-43.

176. Shi J, Gao H, Wang H, Lafitte HR, Archibald RL, Yang M, Hakimi SM, Mo H, Habben JE. ARGOS8 variants generated by CRISPR-Cas9 improve maize grain yield under field drought stress conditions. Plant Biotechnol J. 2017;15(2):207-16.

177. Char SN, Neelakandan AK, Nahampun H, Frame B, Main M, Spalding MH, Becraft PW, Meyers BC, Walbot V, Wang K et al. An Agrobacteriumdelivered CRISPR/Cas9 system for high-frequency targeted mutagenesis in maize. Plant Biotechnol J. 2017;15(2):257-68.

178. Collonnier C, Epert A, Mara K, Maclot F, Guyon-Debast A, Charlot F, White C, Schaefer DG, Nogue F. CRISPR-Cas9-mediated efficient directed mutagenesis and RAD51-dependent and RAD51-independent gene targeting in the moss Physcomitrella patens. Plant Biotechnol J. 2017;15(1):122-31.

179. Lopez-Obando M, Hoffmann B, Gery C, Guyon-Debast A, Teoule E, Rameau C, Bonhomme S, Nogue F. Simple and efficient targeting of multiple genes through CRISPR-Cas9 in Physcomitrella patens. G3 (Bethesda). 2016;6(11):3647-53. doi:10.1534/g3.116.033266.

180. Wang Q, Lu Y, Xin Y, Wei L, Huang S, Xu J. Genome editing of model oleaginous microalgae Nannochloropsis spp. by CRISPR/Cas9. Plant J. 2016;88(6):1071-81.

181. Nekrasov V, Staskawicz B, Weigel D, Jones JD, Kamoun S. Targeted mutagenesis in the model plant Nicotiana benthamiana using Cas9 RNA-guided endonuclease. Nat Biotechnol. 2013;31(8):691-3.

182. Belhaj K, Chaparro-Garcia A, Kamoun S, Nekrasov V. Plant genome editing made easy: targeted mutagenesis in model and crop plants using the CRISPR/Cas system. Plant Methods. 2013;9(1):39.

183. Upadhyay SK, Kumar J, Alok A, Tuli R. RNA-guided genome editing for target gene mutations in wheat. G3 (Bethesda). 2013;3(12):2233-8.

184. Yin K, Han T, Liu G, Chen T, Wang Y, Yu AY, Liu Y. A geminivirus-based guide RNA delivery system for CRISPR/Cas9 mediated plant genome editing. Sci Rep. 2015;5:14926. doi:10.1038/srep14926.

185. Vazquez-Vilar M, Bernabe-Orts JM, Fernandez-Del-Carmen A, Ziarsolo P, Blanca J, Granell A, Orzaez D. A modular toolbox for gRNA-Cas9 genome engineering in plants based on the GoldenBraid standard. Plant Methods. 2016;12:10.

186. Gao J, Wang G, Ma S, Xie X, Wu X, Zhang X, Wu Y, Zhao P, Xia Q. CRISPR/ Cas9-mediated targeted mutagenesis in Nicotiana tabacum. Plant Mol Biol. 2015;87(1-2):99-110.
187. Mercx S, Tollet J, Magy B, Navarre C, Boutry M. Gene inactivation by CRISPRCas9 in Nicotiana tabacum BY-2 suspension cells. Front Plant Sci. 2016;7:40.

188. Zhang B, Yang X, Yang C, Li M, Guo Y. Exploiting the CRISPR/Cas9 system for targeted genome mutagenesis in petunia. Sci Rep. 2016;6:20315.

189. Subburaj S, Chung SJ, Lee C, Ryu SM, Kim DH, Kim JS, Bae S, Lee GJ. Site-directed mutagenesis in Petunia x hybrida protoplast system using direct delivery of purified recombinant Cas9 ribonucleoproteins. Plant Cell Rep. 2016;35(7):1535-44.

190. Fan D, Liu T, Li C, Jiao B, Li S, Hou Y, Luo K. Efficient CRISPR/Cas9-mediated targeted mutagenesis in populus in the first generation. Sci Rep. 2015;5:12217.

191. Tingting L, Di F, Lingyu R, Yuanzhong J, Rui L, Keming L. Highly efficient CRISPR/Cas9-mediated targeted mutagenesis of multiple genes in Populus. Yi Chuan. 2015;37(10):1044-52.

192. Wang S, Zhang S, Wang W, Xiong X, Meng F, Cui X. Efficient targeted mutagenesis in potato by the CRISPR/Cas9 system. Plant Cell Rep. 2015;34(9):1473-6.

193. Butler NM, Atkins PA, Voytas DF, Douches DS. Generation and inheritance of targeted mutations in potato (Solanum tuberosum L.) using the CRISPR/Cas System. PLoS ONE. 2015;10(12):e0144591.

194. Andersson M, Turesson H, Nicolia A, Falt AS, Samuelsson M, Hofvander P. Efficient targeted multiallelic mutagenesis in tetraploid potato (Solanum tuberosum) by transient CRISPR-Cas9 expression in protoplasts. Plant Cell Rep. 2017;36(1):117-28. doi:10.1007/s00299-016-2062-3.

195. Zhou X, Zha M, Huang J, Li L, Imran M, Zhang C. StMYB44 negatively regulates phosphate transport by suppressing expression of PHOSPHATE1 in potato. J Exp Bot. 2017. doi:10.1093/jxb/erx026.

196. Xie K, Yang Y. RNA-guided genome editing in plants using a CRISPR-Cas system. Mol Plant. 2013;6(6):1975-83.

197. Zhang H, Zhang J, Wei P, Zhang B, Gou F, Feng Z, Mao Y, Yang L, Zhang $\mathrm{H}$, Xu N, et al. The CRISPR/Cas9 system produces specific and homozygous targeted gene editing in rice in one generation. Plant Biotechnol J. 2014;12(6):797-807.

198. Ma L, Zhang D, Miao Q, Yang J, Xuan Y, Hu Y. Essential role of sugar transporter OsSWEET11 during the early stage of rice grain filling. Plant Cell Physiol. 2017. doi:10.1093/pcp/pcx040.

199. Miao J, Guo D, Zhang J, Huang Q, Qin G, Zhang X, Wan J, Gu H, Qu LJ. Targeted mutagenesis in rice using CRISPR-Cas system. Cell Res. 2013;23(10):1233-6.

200. Xu R, Li H, Qin R, Wang L, Li L, Wei P, Yang J. Gene targeting using the Agrobacterium tumefaciens-mediated CRISPR-Cas system in rice. Rice (NY). 2014;7(1):5

201. Endo M, Mikami M, Toki S. Multigene knockout utilizing off-target mutations of the CRISPR/Cas9 system in rice. Plant Cell Physiol. 2015;56(1):41-7.

202. Xie K, Minkenberg B, Yang Y. Boosting CRISPR/Cas9 multiplex editing capability with the endogenous tRNA-processing system. Proc Natl Acad Sci USA. 2015;112(11):3570-5.

203. Xu RF, Li H, Qin RY, Li J, Qiu CH, Yang YC, Ma H, Li L, Wei PC, Yang JB. Generation of inheritable and "transgene clean" targeted genomemodified rice in later generations using the CRISPR/Cas9 system. Sc Rep. 2015;5:11491.

204. Mikami M, Toki S, Endo M. Parameters affecting frequency of CRISPR/Cas9 mediated targeted mutagenesis in rice. Plant Cell Rep. 2015;34(10):1807-15.

205. Mikami M, Toki S, Endo M. Comparison of CRISPR/Cas9 expression constructs for efficient targeted mutagenesis in rice. Plant Mol Biol. 2015;88(6):561-72.

206. Hu X, Wang C, Fu Y, Liu Q, Jiao X, Wang K. Expanding the range of CRISPR/Cas9 genome editing in rice. Mol Plant. 2016;9(6):943-5.

207. Zheng X, Yang S, Zhang D, Zhong Z, Tang X, Deng K, Zhou J, Qi Y, Zhang Y. Effective screen of CRISPR/Cas9-induced mutants in rice by singlestrand conformation polymorphism. Plant Cell Rep. 2016;35:1545-54.

208. Osakabe Y, Watanabe T, Sugano SS, Ueta R, Ishihara R, Shinozaki K, Osakabe K. Optimization of CRISPR/Cas9 genome editing to modify abiotic stress responses in plants. Sci Rep. 2016:6:26685.

209. Liu L, Zheng C, Kuang B, Wei L, Yan L, Wang T. Receptor-like kinase RUPO interacts with potassium transporters to regulate pollen tube growth and integrity in rice. PLoS Genet. 2016;12(7):e1006085. 
210. Li J, Meng X, Zong Y, Chen K, Zhang H, Liu J, Li J, Gao C. Gene replacements and insertions in rice by intron targeting using CRISPR-Cas9. Nat Plants. 2016;2:16139.

211. Liu Y, Xu Y, Ling S, Liu S, Yao J. Anther-preferential expressing gene PMR is essential for the mitosis of pollen development in rice. Plant Cell Rep. 2017. doi:10.1007/s00299-017-2123-2.

212. Yuan J, Chen S, Jiao W, Wang L, Wang L, Ye W, Lu J, Hong D, You S, Cheng $Z$ et al. Both maternally and paternally imprinted genes regulate seed development in rice. New Phytol. 2017. doi:10.1111/nph.14510.

213. Li X, Zhou W, Ren Y, Tian X, Lv T, Wang Z, Fang J, Chu C, Yang J, Bu Q. High-efficiency breeding of early-maturing rice cultivars via CRISPR/ Cas9-mediated genome editing. J Genet Genom. 2017;44(3):175-8.

214. Sun Y, Jiao G, Liu Z, Zhang X, Li J, Guo X, Du W, Du J, Francis F, Zhao Y et al. Generation of high-amylose rice through CRISPR/Cas9-mediated targeted mutagenesis of starch branching enzymes. Front Plant Sci. 2017:8:298. doi:10.3389/fpls.2017.00298.

215. Yamauchi T, Yoshioka M, Fukazawa A, Mori H, Nishizawa NK, Tsutsumi $\mathrm{N}$, Yoshioka H, Nakazono M. An NADPH oxidase RBOH functions in rice roots during lysigenous aerenchyma formation under oxygen-deficient conditions. Plant Cell. 2017. doi:10.1105/tpc.16.00976.

216. Li B, Cui G, Shen G, Zhan Z, Huang L, Chen J, Qi X. Targeted mutagenesis in the medicinal plant Salvia miltiorrhiza. Sci Rep. 2017:7:43320.

217. Jacobs TB, LaFayette PR, Schmitz RJ, Parrott WA. Targeted genome modifications in soybean with CRISPR/Cas9. BMC Biotechnol. 2015:15:16.

218. Sun $X, H u Z$, Chen $R$, Jiang $Q$, Song G, Zhang $H$, Xi Y. Targeted mutagenesis in soybean using the CRISPR-Cas9 system. Sci Rep. 2015:5:10342.

219. Li Z, Liu ZB, Xing A, Moon BP, Koellhoffer JP, Huang L, Ward RT, Clifton E, Falco SC, Cigan AM. Cas9-guide RNA directed genome editing in soybean. Plant Physiol. 2015;169(2):960-70.

220. Cai Y, Chen L, Liu X, Sun S, Wu C, Jiang B, Han T, Hou W. CRISPR/ Cas9-mediated genome editing in soybean hairy roots. PLoS ONE. 2015;10(8):e0136064.

221. Jia H, Wang N. Targeted genome editing of sweet orange using Cas9/ sgRNA. PLOS ONE. 2014;9(4):e93806.

222. Peng A, Chen S, Lei T, Xu L, He Y, Wu L, Yao L, Zou X. Engineering canker-resistant plants through CRISPR/Cas9-targeted editing of the susceptibility gene CsLOB1 promoter in citrus. Plant Biotechnol J. 2017. doi:10.1111/pbi.12733.
223. Ron M, Kajala K, Pauluzzi G, Wang D, Reynoso MA, Zumstein K, Garcha J, Winte S, Masson H, Inagaki S, et al. Hairy root transformation using Agrobacterium rhizogenes as a tool for exploring cell type-specific gene expression and function using tomato as a model. Plant Physiol. 2014;166(2):455-69.

224. Brooks C, Nekrasov V, Lippman ZB, Van Eck J. Efficient gene editing in tomato in the first generation using the clustered regularly interspaced short palindromic repeats/CRISPR-associated9 system. Plant Physiol. 2014:166(3):1292-7.

225. Ito Y, Nishizawa-Yokoi A, Endo M, Mikami M, Toki S. CRISPR/Cas9-mediated mutagenesis of the RIN locus that regulates tomato fruit ripening. Biochem Biophys Res Commun. 2015;467(1):76-82.

226. Pan C, Ye L, Qin L, Liu X, He Y, Wang J, Chen L, Lu G. CRISPR/Cas9-mediated efficient and heritable targeted mutagenesis in tomato plants in the first and later generations. Sci Rep. 2016;6:24765.

227. Klap C, Yeshayahou E, Bolger AM, Arazi T, Gupta SK, Shabtai S, Usadel $B$, Salts Y, Barg R. Tomato facultative parthenocarpy results from SIAGAMOUS-LIKE 6 loss of function. Plant Biotechnol J. 2016. doi:10.1111/ pbi.12662.

228. Soyk S, Muller NA, Park SJ, Schmalenbach I, Jiang K, Hayama R, Zhang L, Van Eck J, Jimenez-Gomez JM, Lippman ZB. Variation in the flowering gene SELF PRUNING 5 G promotes day-neutrality and early yield in tomato. Nat Genet. 2017:49(1):162-8.

229. Xu C, Park SJ, Van Eck J, Lippman ZB. Control of inflorescence architecture in tomato by BTB/POZ transcriptional regulators. Genes Dev. 2016;30(18):2048-61.

230. Ueta R, Abe C, Watanabe T, Sugano SS, Ishihara R, Ezura H, Osakabe Y, Osakabe K. Rapid breeding of parthenocarpic tomato plants using CRISPR/Cas9. Sci Rep. 2017:7(1):507.

231. Nekrasov V, Wang C, Win J, Lanz C, Weigel D, Kamoun S. Rapid generation of a transgene-free powdery mildew resistant tomato by genome deletion. Sci Rep. 2017;7(1):482.

\section{Submit your next manuscript to BioMed Central and we will help you at every step:}

- We accept pre-submission inquiries

- Our selector tool helps you to find the most relevant journal

- We provide round the clock customer support

- Convenient online submission

- Thorough peer review

- Inclusion in PubMed and all major indexing services

- Maximum visibility for your research

Submit your manuscript at www.biomedcentral.com/submit
O Biomed Central 